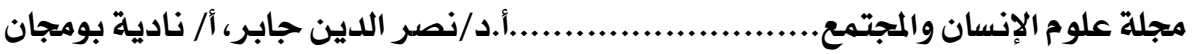

\title{
الإتجاهات الرائدة في الإرشاد المعرفي السلوكي
}

الأستاذ الدكتور : نصر الدين جابر ، جامعة بسكرة، الجزائر

الأستاذة: نادية بومجان، جامعة بسكرة، الجزائر

الملخص:

يعد الإرشاد المعرفي السلوكى من أكثر الاتجاهات شيوعا في الوقت

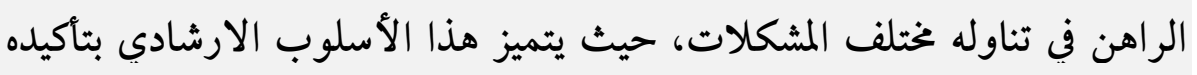

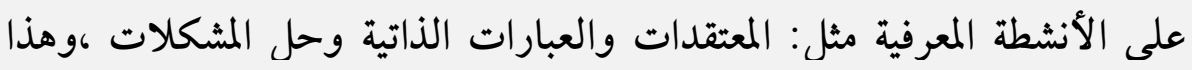

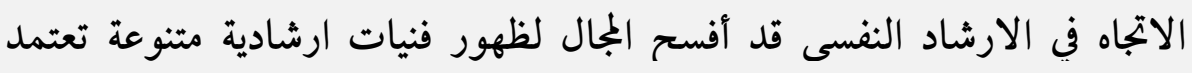

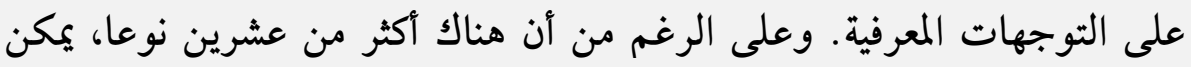

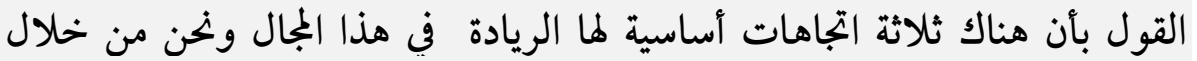

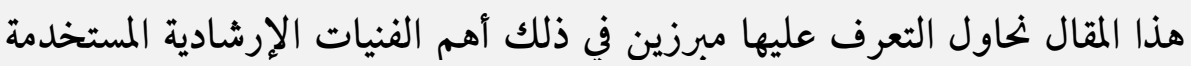

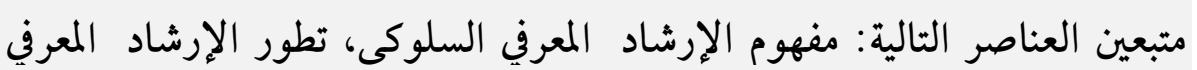

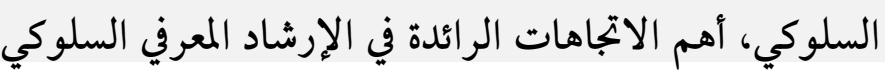

\section{Résumé:}

La guidance cognitivo-comportementale est des tendances les plus communs à l'heure actuelle en abordant divers problèmes où ce style indicatif affirmant sur les activités cognitives telles que : les croyances et les auto-expressions et la résolution de problèmes, et cette tendance de counseling psychologique a permis l'émergence d'une variété de techniques d'extension repose sur les orientations cognitives, bien qu'il existe plus de vingt genres, on peut dire qu'il y a trois tendances fondamentales menant dans ce domaine et à travers cet article, nous essayons d'identifier le concept de guidance cognitivo-comportementale et ensuite l'évolution de ce type de traitement pour Principales tendances en mettant en évidence les plus importantes techniques thérapeutiques utilisées. 
مقدمة:

يعتبر الإرشاد (العلاج)" المعرفي السلوكي أحد طرق الإرشاد النفسي التي

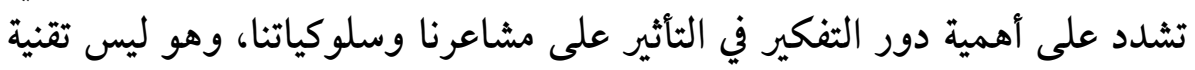

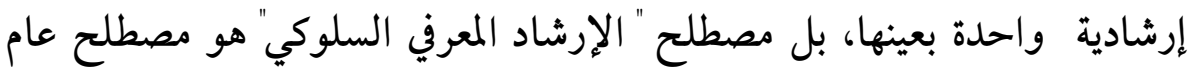

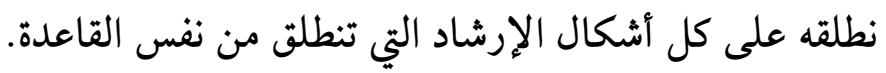
وحسب بيك فان الارشاد المعرفي السلوكي عبارة عن مظلة تنطوي على العديد

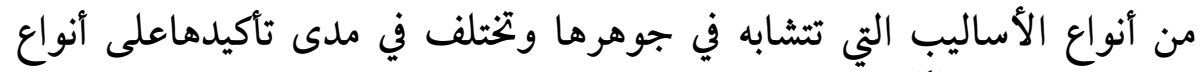
معينة من الفنيات (1).

وهناك العديد من اشكال العلاج المعرفي السلوكي مثل: العلاج العقلاني

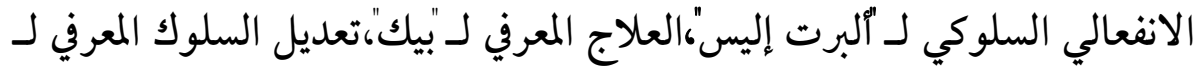

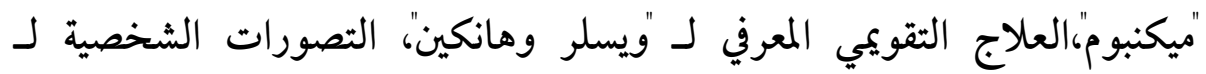

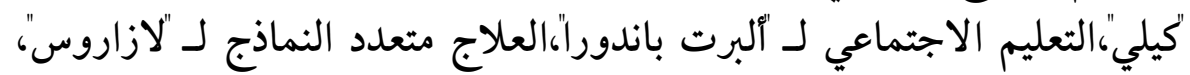

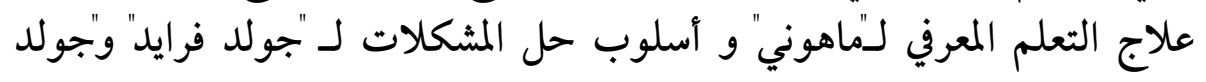
فرايد." - في

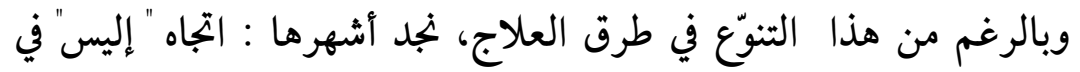

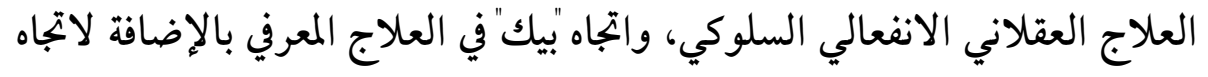

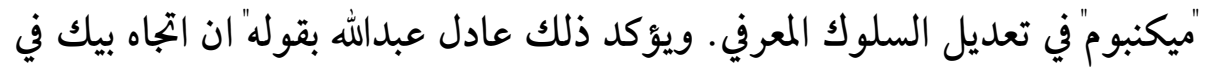

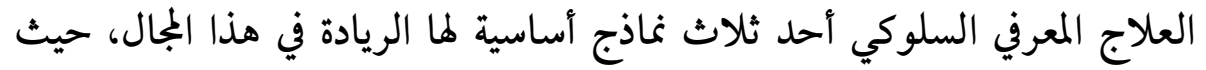

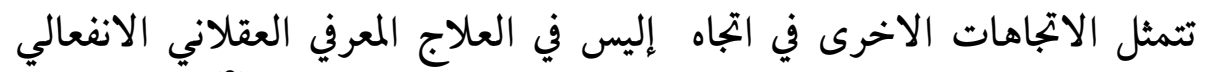

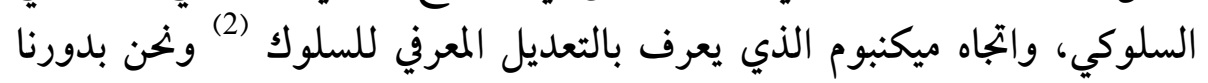

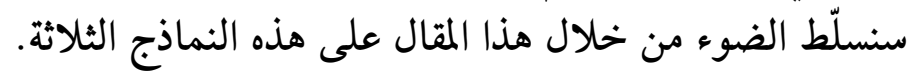

أولا: مفهوم الإرشاد المعرفي السلوكي: 1. تعريف الإرشاد السلوكي: 


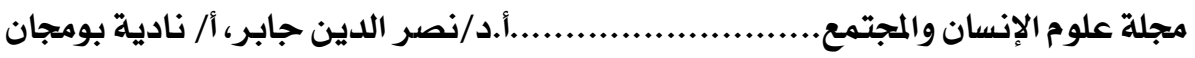

يعتبر الإرشاد السلوكي أحد الأساليب الحديثة المبنية في الأساس على

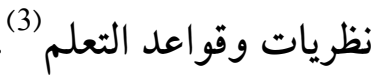

ووفق النظرية السلوكية فإن التعلم يعتبر تغيرا في السلوك، ليس بسبب

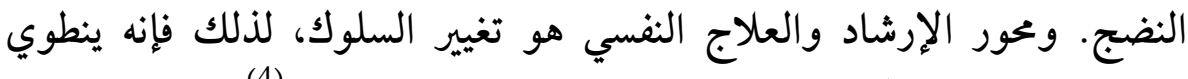

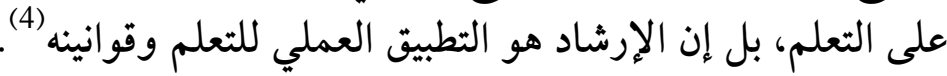

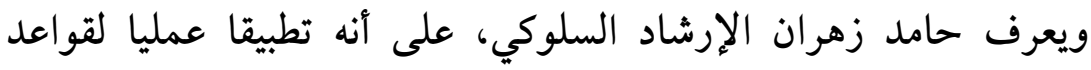

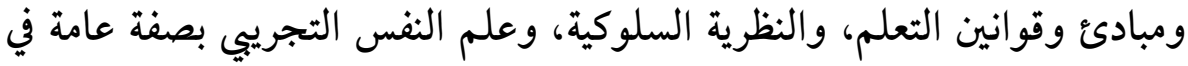

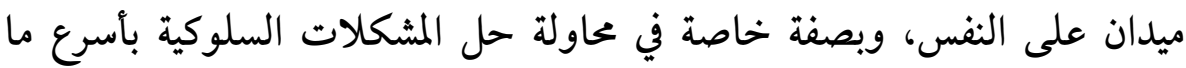

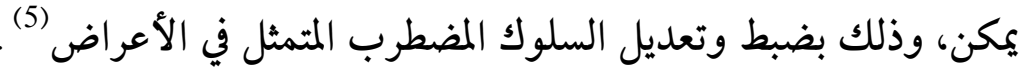
ويعرف" كرمبولتز وثوريسن " krumboltz, thoreson الإرشاد السلوكي

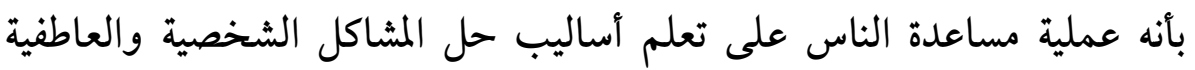

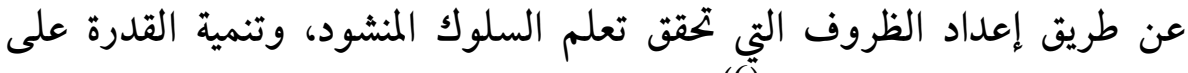

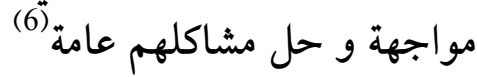

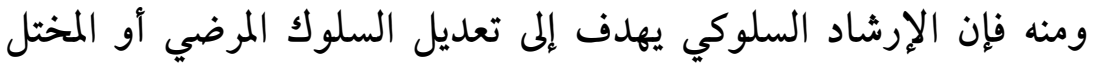

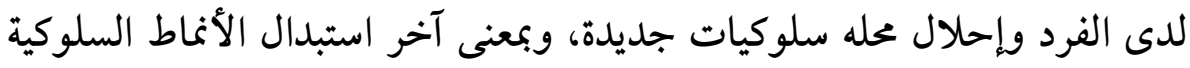
غير المرغوب فيها من الظهور وهو ما يعرف بالكف النقيض أو الكف المنتبادل،

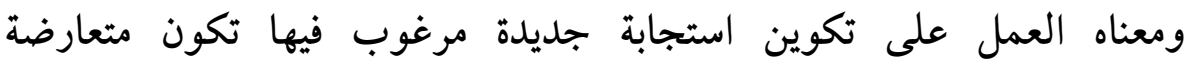

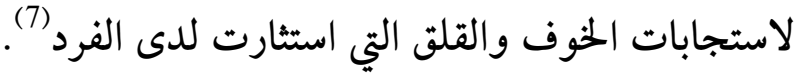

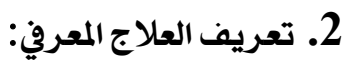

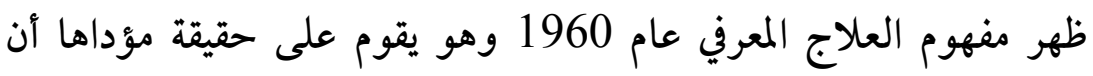

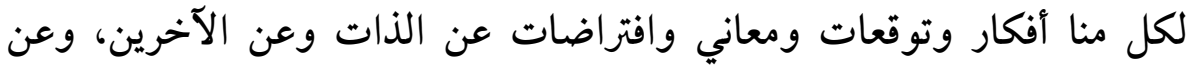

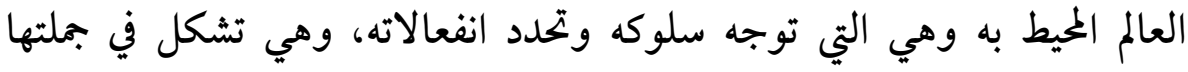
الفلسفة الأساسية للشخص في الحياة، وان المشكلات والصعوبات النفسية (قلق، 
اكتئاب، عدوان وغيرة) في الحياة تحدث عندما تكون هذه الأفكار والاعتقادات والافتراضات لديه ذات طبيعة سلبية وخاطئة (8)

وقد كان العلاج المعرفي منذ أكثر من عشرين سنة مضت مقصورا على

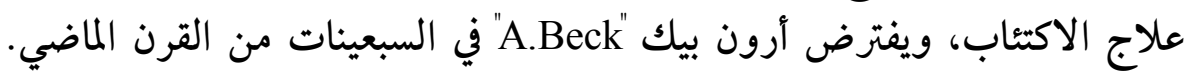

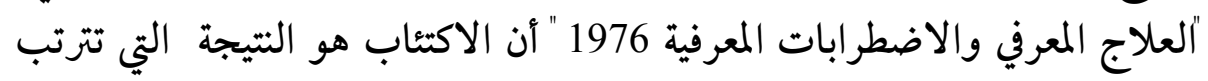

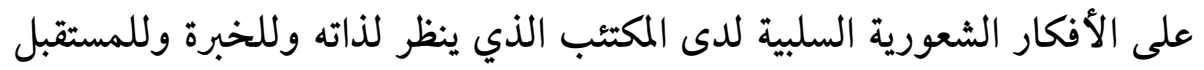

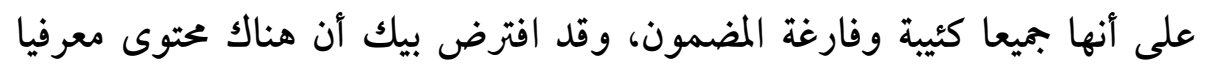
معينا يميز كل اضطراب نفسي. وأن هدف العلاج هو تحديد وتعديل تحريفات وتحيزات التفكير لدى المريض، وكذلك تحديد وتعديل المخطط المعرفي الخاص لدى المريض (9). ويمكن تعريف العلاج المعرفي كما يلي: هو ذلك العلاج الذي يستند على النموذج المعرفي الذي يفترض أن

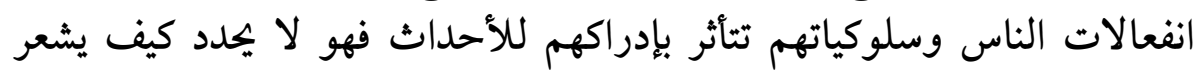

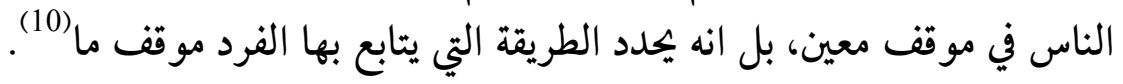

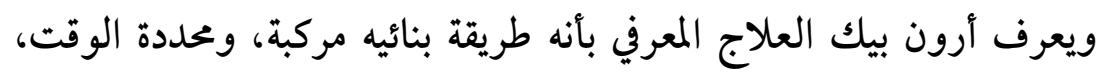

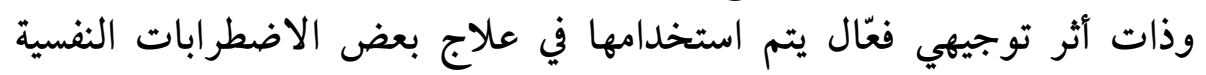
مثل : القلق، والاكتئاب، والمخاوف المرضية، ومشكلات التال الألم وغيرها. ويعرّف أيضا بأنه شكل من أشكال العلاج النفسي، يقوم على فكرة

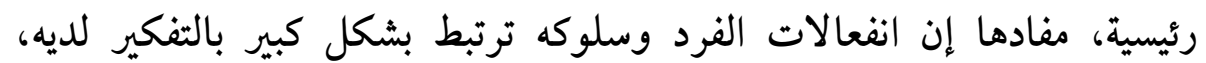
فإدراك وتفسير الأحداث يؤثر في الاستجابات الانفعالية والسلوكية للفرد، وان انفان

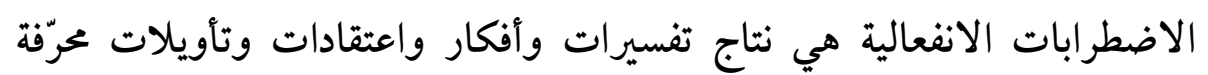
ومشوّهة لخبرات الحياة. 


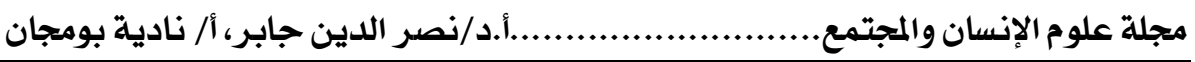

معنى ذلك أن الطريقة التي يفكر بها الفرد ويدرك بها الموقف تكون مرتبطة

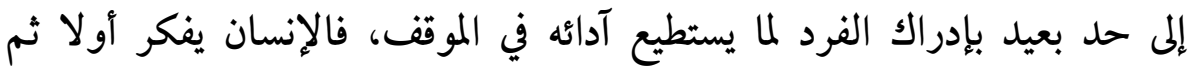

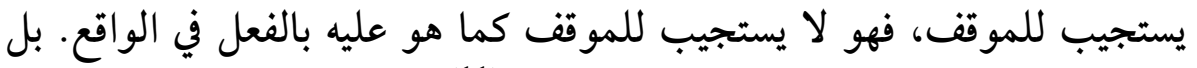

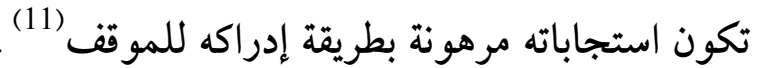
ونخلص في الأخير إلى أن العلاج المعرفي يركز على تغيير أفكار الفرد بحيث يتغير سلوكه وحالثه الانفعالية.

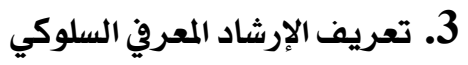
ظهر مصطلح الإرشاد (العلاج) المعرفي السلوكي في بداية الثلث الأخير

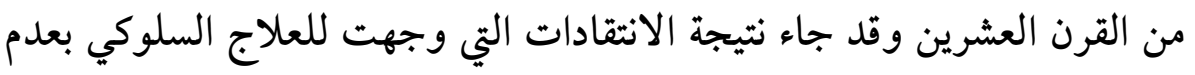

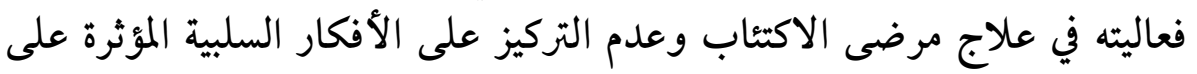

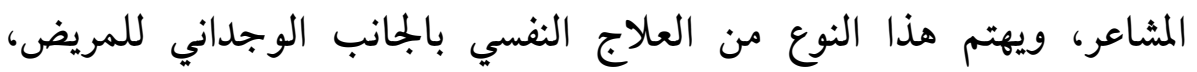

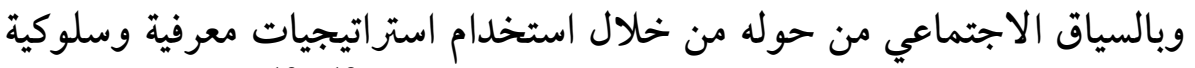

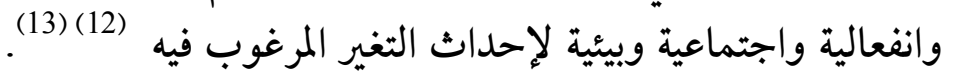

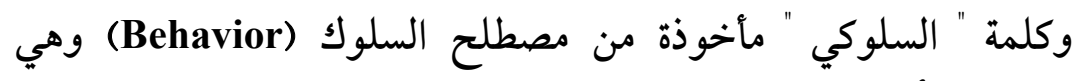

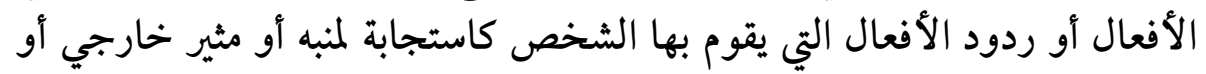

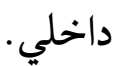

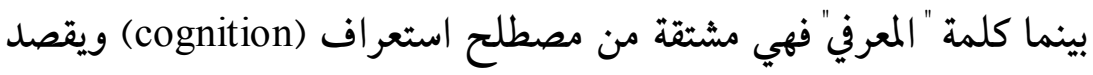

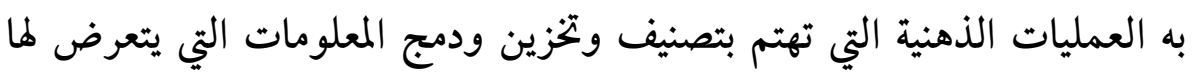

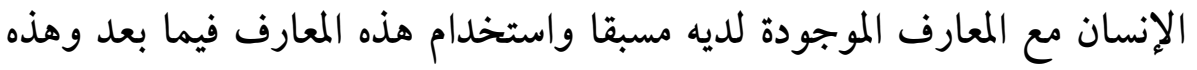

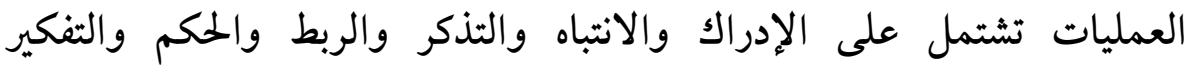
الواعي (14) 
ويستخدم مصطلح "معرفي - سلوكي" ليشير بصفة عامة إلى العلاج النفسي

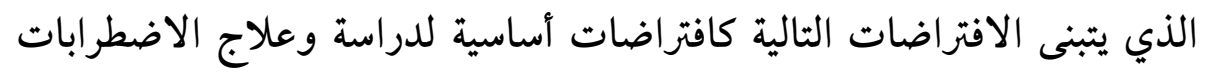
النفسية متضمنة فيها العلاج المعرفي الذي وصفه بيك عام 1979. تلك الافتراضات الأساسية هي: 1. الأنشطة المعرفية تؤثر في السلوك.

2. الأنشطة المعرفية من الممكن مراقبتها وتغيرها.

3. التغير المرغوب للسلوك قد يتم من خلال التغيير المعرفي (15).

كما يمثل الإرشاد السلوكي المعرفي "السلوكية المنهجية " Methodological Behaviorsm

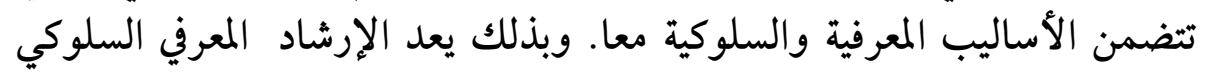

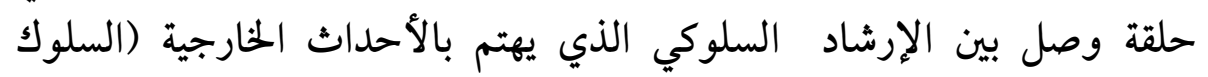
الظاهر) والإرشاد المعرفي الذي يهتم بالأحداث الداخلية الذادي (العمليات المعرفية) معتبرا أن السلوك الظاهري وعملية الإدراك والتفكير يشكلان معا حلقة وصل. وقد اشترك المنهجان المعرفي والسلوكي في أن كلاّ منها: > يركز على الأعراض الظاهرة أكثر مما يركز على أسباب دينامية مفترضة.

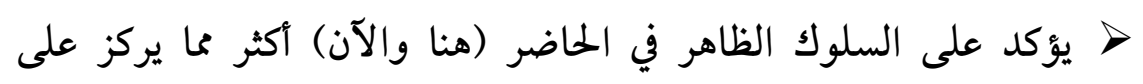
خبرات الماضي.

> يشارك المعالج باييجابية في إعداد برنامج علاجي معين (16). ويعرف جلاس وشيا Glass \& shea" "الإرشاد المعرفي السلوكي 1986

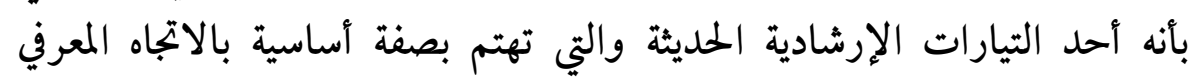

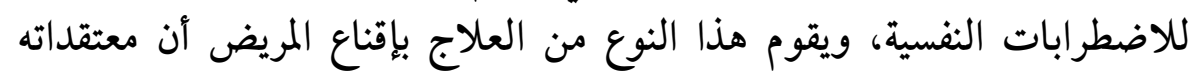

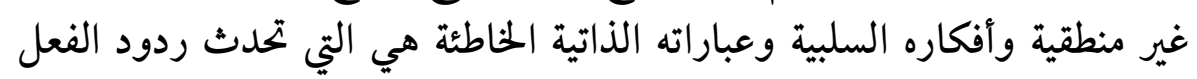




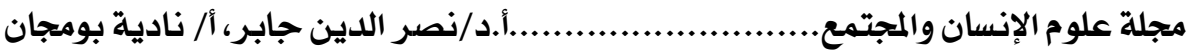

الدالة على سوء التكيف بهدف تعديل الجوانب المعرفية المشوّهة والعمل على أن أن

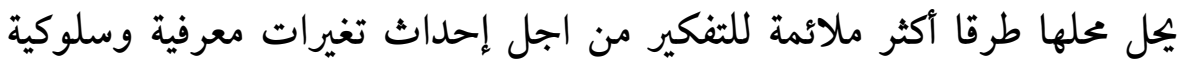
ووجدانية لدى العميل (17). ويعرف" لويس مليكة "الإرشاد المعرفي السلوكي بأنه: أحد المناهج الإرشادية التي تهدف إلى تعديل السلوك الظاهر من خلال التأثير في عمليات التفكير عن طريق: 1. التدريب على مهارات المواجهة.

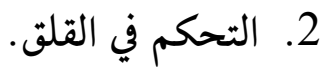

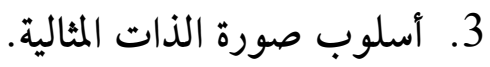

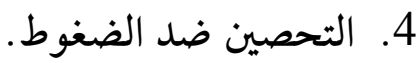
5. التدريب على حل المشكلة.

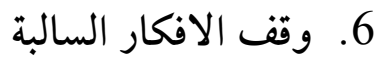
7. - (التعلم الذاتي (18).

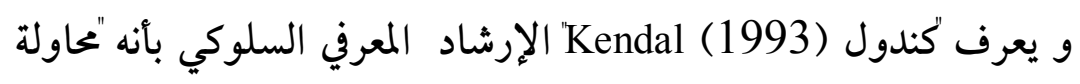

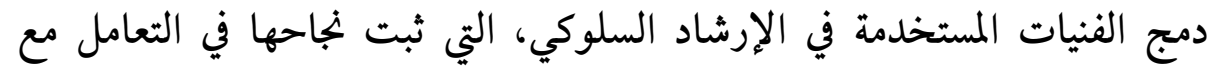

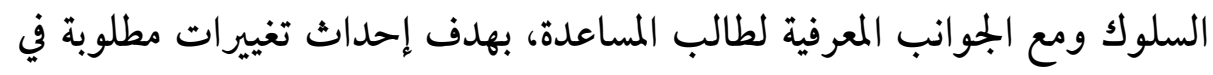

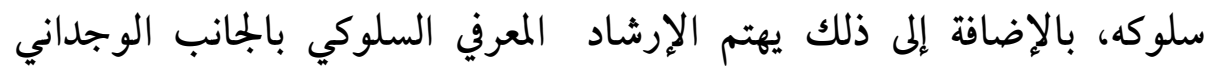

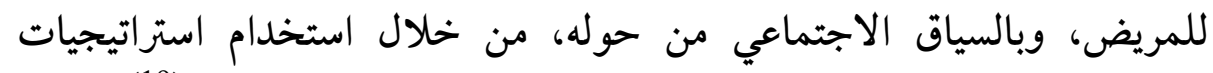
معرفية، سلوكية، انفعالية، اجتماعية وبيئة لإحداث التئية التغيير المرغوب فيه (19). ويعرف "ستيفين" و "بيك" Steven \& Beak الإرشاد المعرفي السلوكي بأنه

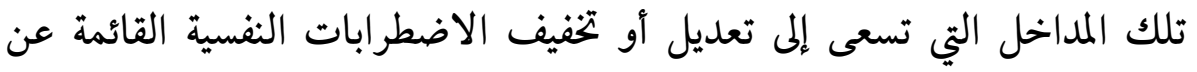
طريق المفاهيم الذهنية الخاطئة او العمليات المعرفية. 


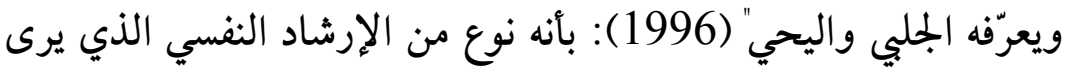

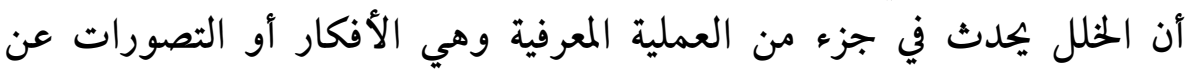

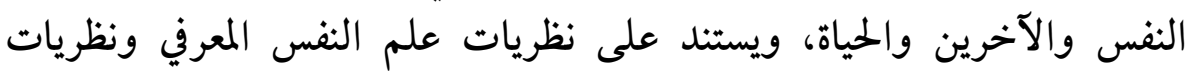
معالجة المعلومات ونظريات علم النفس الاجتماعي.

ويعرفه برين (Brewin (1996، بأنه التدخل الإرشادي ببعض الفنيات

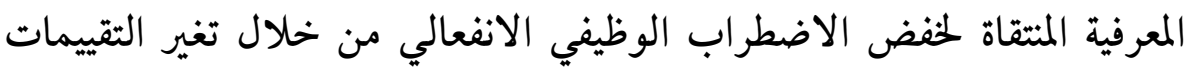

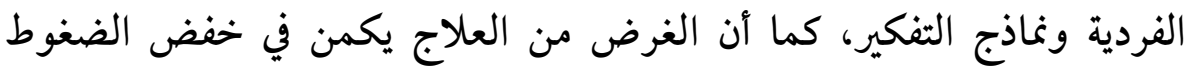

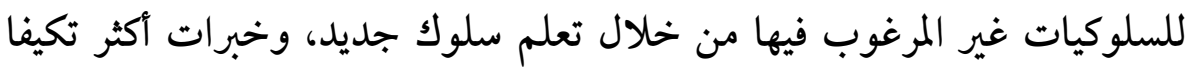

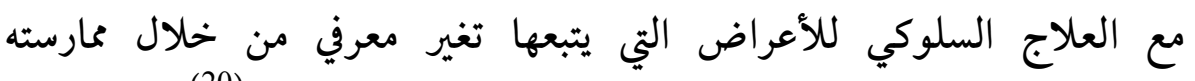
سلوكيات جديدة وتحليل أخطاء التفكير وتعلم أحاديث ذاتية أكثر (20).

ومن خلال التعريفات السابقة نخلص إلى أن الإرشاد المعرفي السلوكي

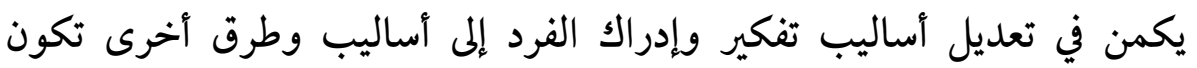

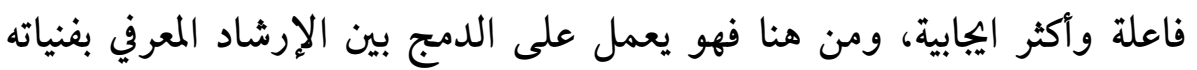

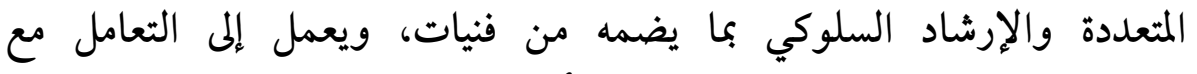

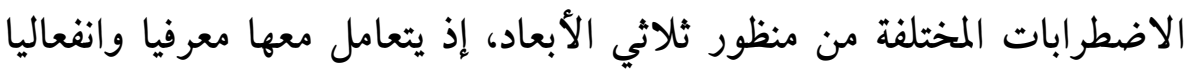

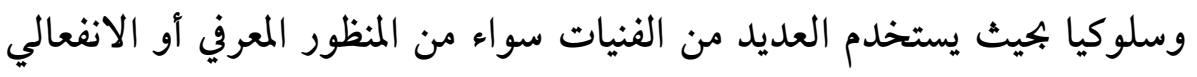

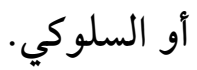

ومن هنا تبرز خصائص استخدام الإرشاد المعرفي السلوكي فهو يعطي

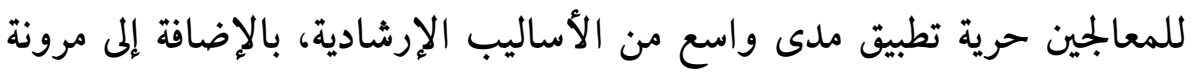

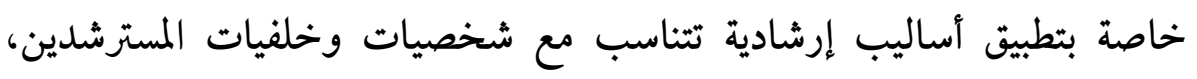

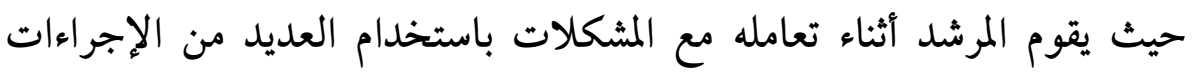

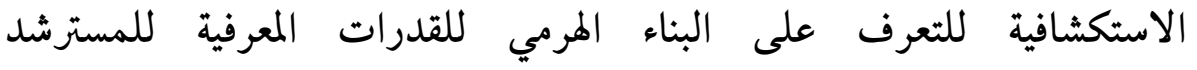

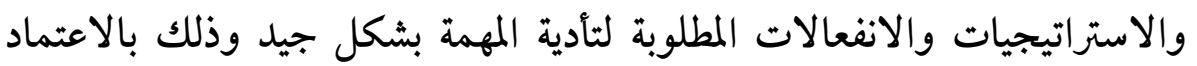
على العديد من الفنيات والأساليب التي تستخدمها النظرية السلوكية المعرفية، 


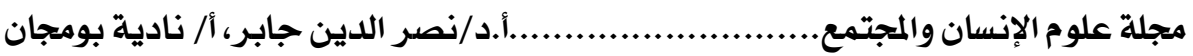

والتي تتناسب مع شخصيات وخلفيات المسترشدين ونوعية المشكلات التي يعانون منها، لذلك فإننا نجد تنوعا كبيرا في الأساليب السلوكية المعرفية واستخدامات متعددة له (21).

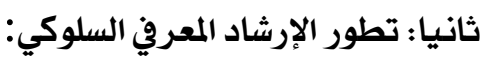

إن ظهور الإرشاد المعرفي السلوكي، كان بمثابة رد فعل على منحى الإرشاد

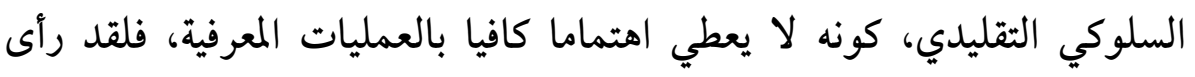

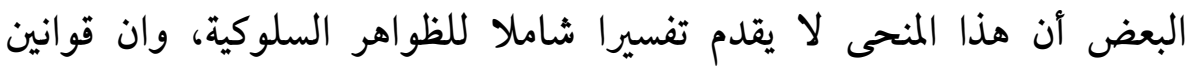

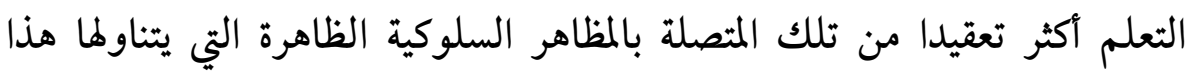

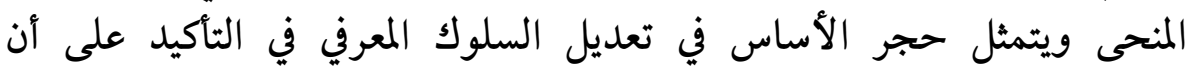

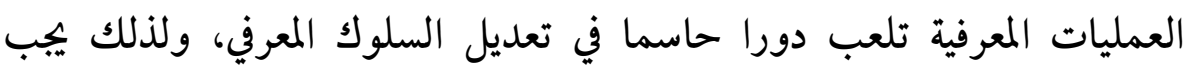

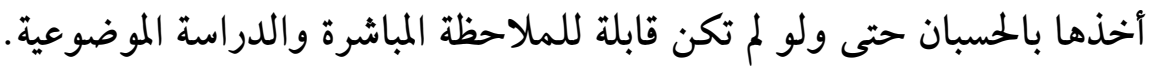
ويقوم بجال الإرشاد السلوكي المعرفي على افتراض أن الإنسان ليس سلبيا

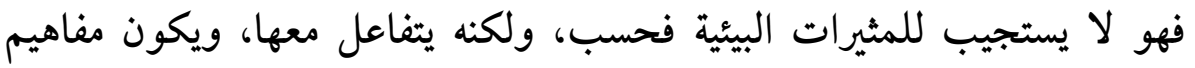

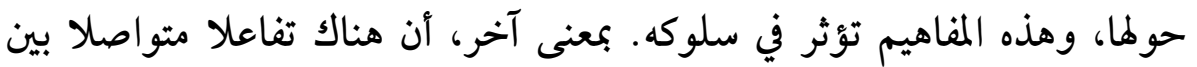

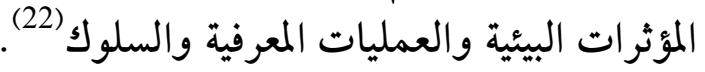

ويمكن تتبع بداية التحول من الإرشاد السلوكي إلى الإرشاد المعرفي-

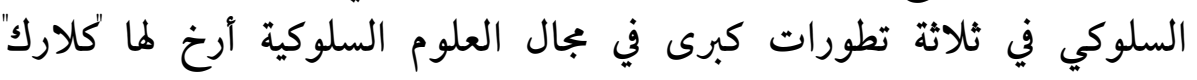

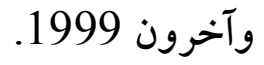

أول واهم هذه التغيرات هو ما حدث في النظرية السلوكية الإكلينيكية

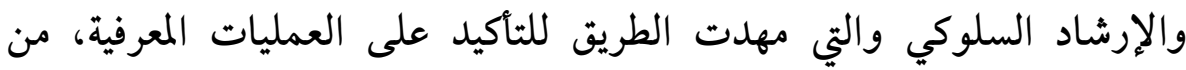

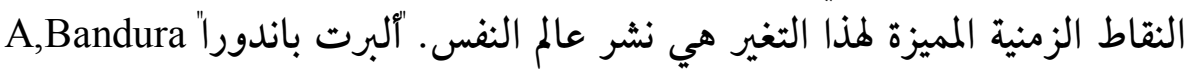

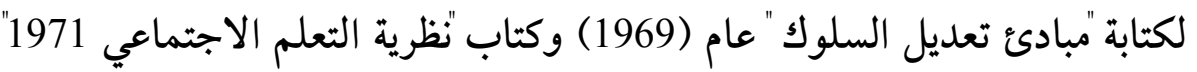

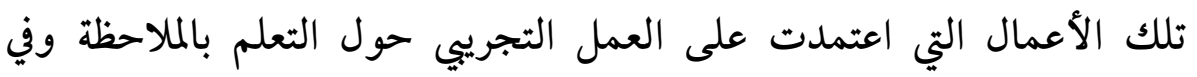

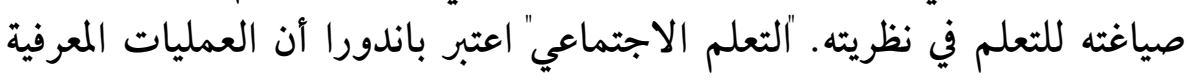


ذات دور خطير في اكتساب وتنظيم السلوك وان البيئة تتؤثر بشكل حتمي، وقد

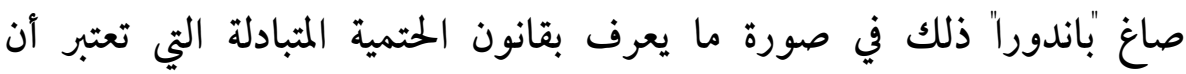

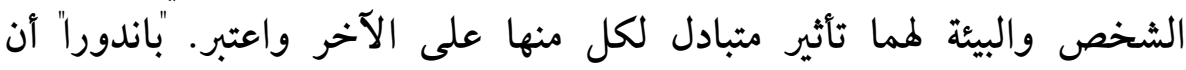

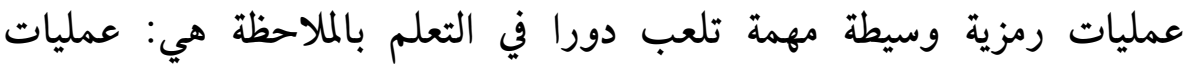

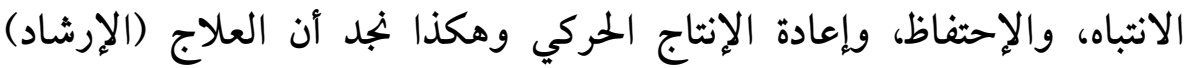

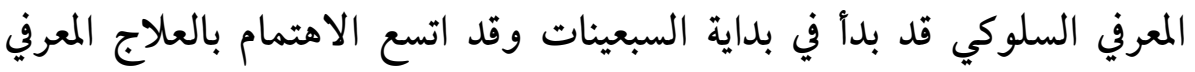

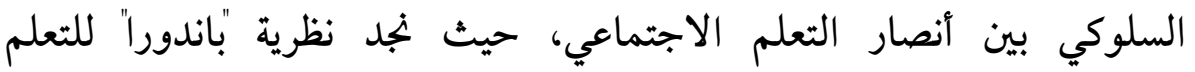

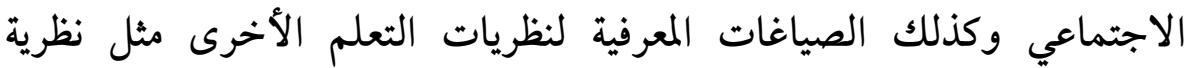

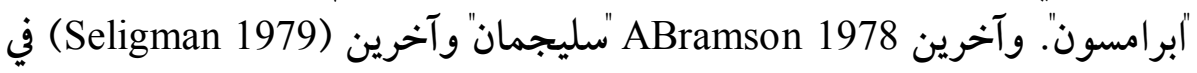

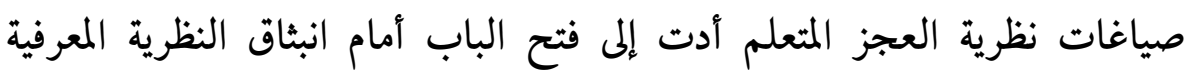
والعلاج المعرفي (25)(25)(25)

الجانب الثاني الأساسي لارتقاء النظرية المعرفية - السلوكية والنظرية

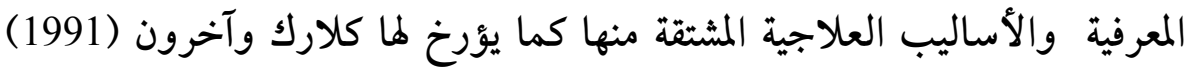

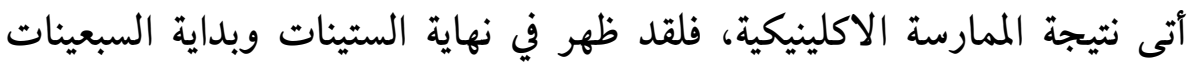

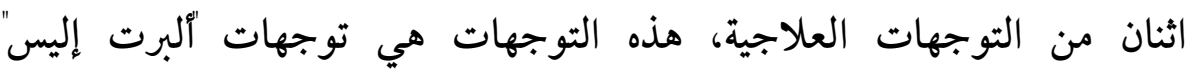
A.ELLIS و "أرون بيك" A.BECK الذين هجرا توجهاتهما التحليلية وتوجها

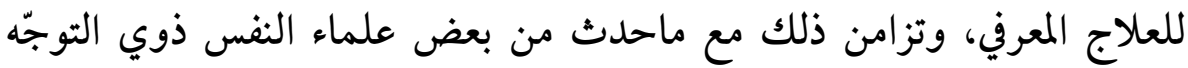

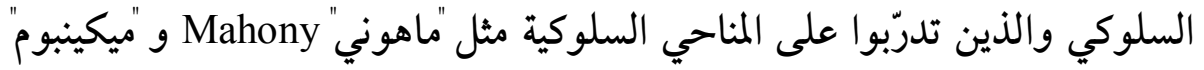
Meicheinbaum و "دافيدسون" Davidson و "جولد فريد" goldfreid فلقد تضمنت فئت

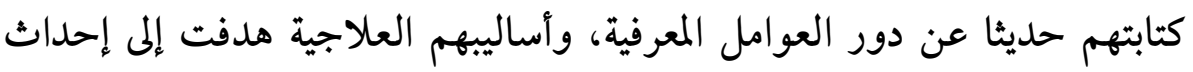
تعديل سلوكي - معرفي للمريض.

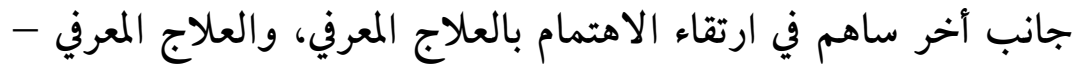

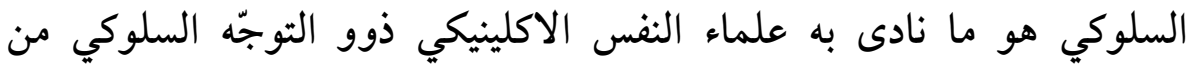

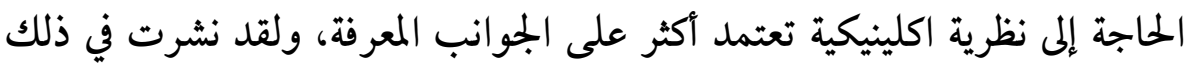




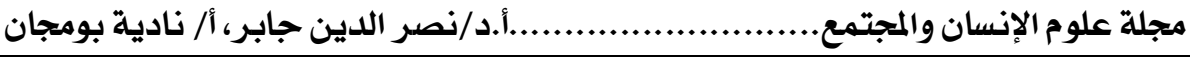

الوقت بعض الكتابات التي طالبت بذلك منها ما ذكره. "مايكل ماهوني" في كتابه

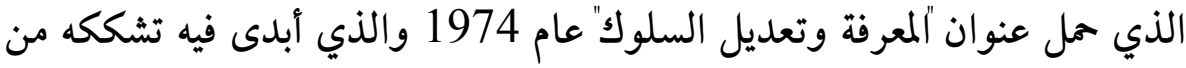

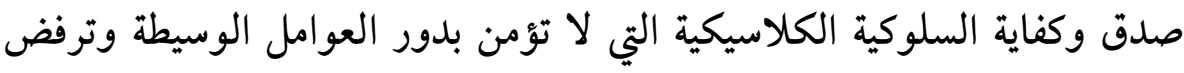

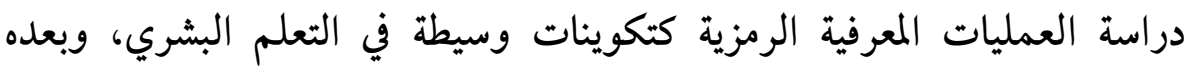

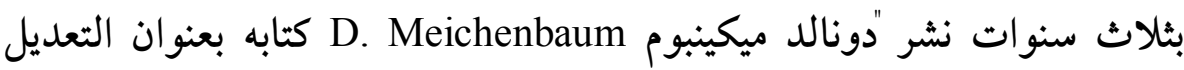

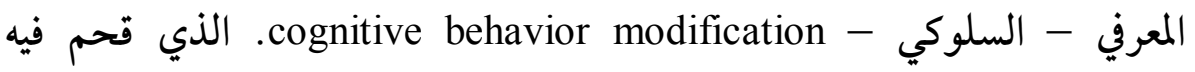

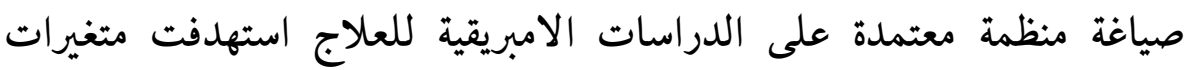
معرفية باستخدام استراتيجيات معرفية وسلوكية.

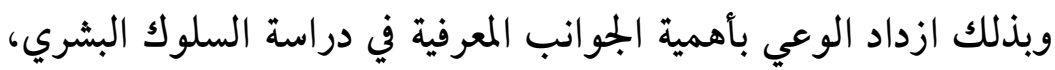

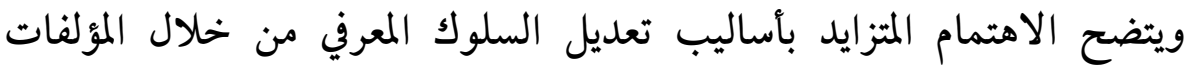

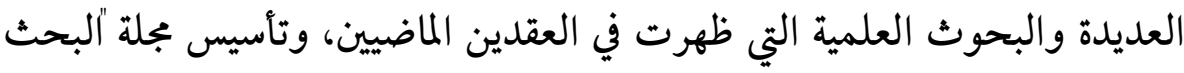

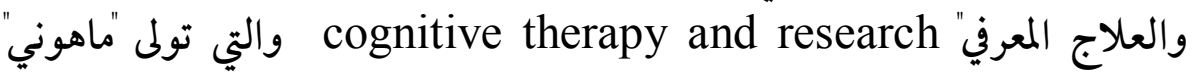

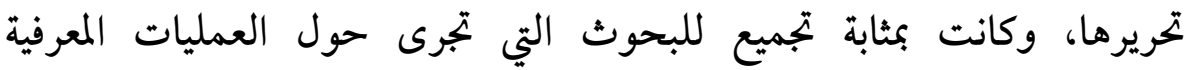

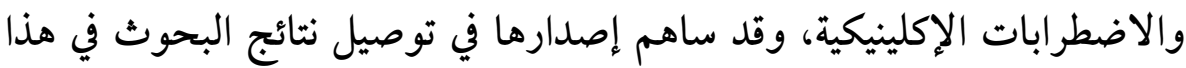

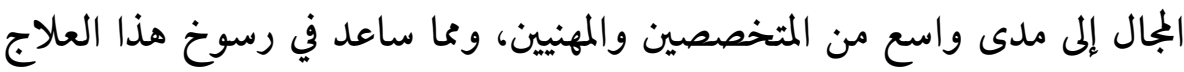

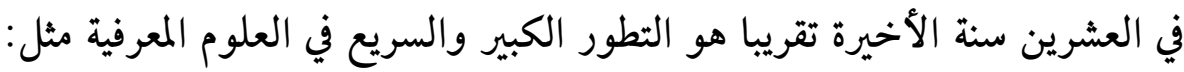

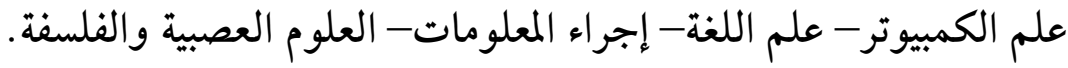

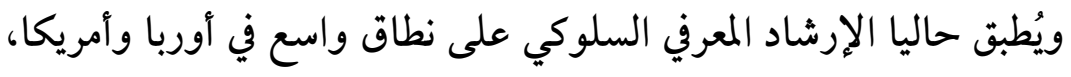

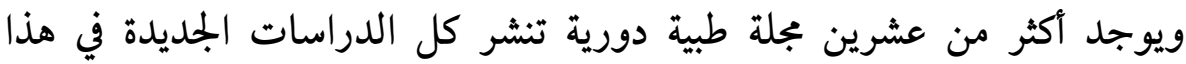
المجال (27) (28) (29)

ويجب الإشارة هنا إلى أن الدراسات والبحوث العلمية التي تجرى في مجال

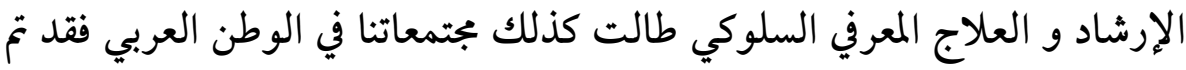

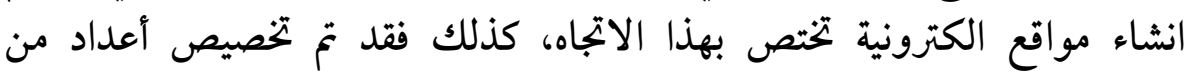

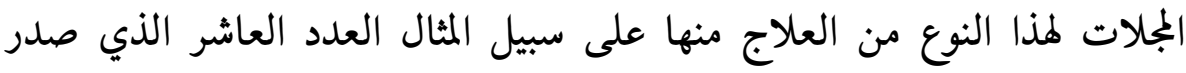




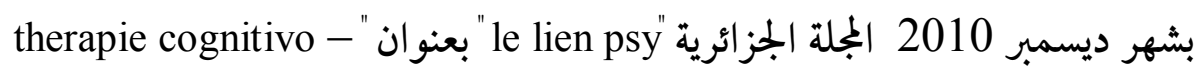

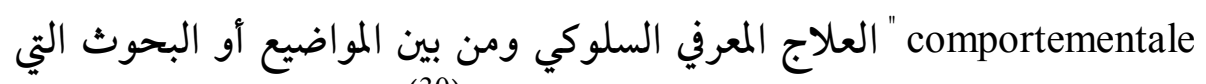
طرحت في المجلة العلاج السلوكي المعرفي للاكتئاب (30). ثالثا: الاتجاهات الرائدة في الإرشاد المعرفي السلوكي

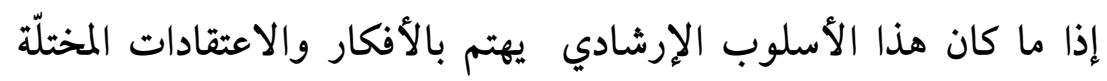
وظيفيا فإن هناك نمطين للإختلال الوظيفي المعرفي:

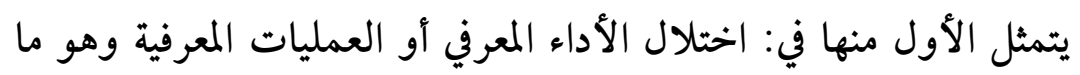
يتضمن تلك المشكلات التي تعوق الأداء المعرفي.

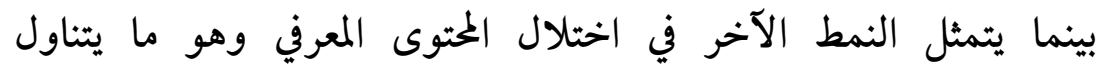

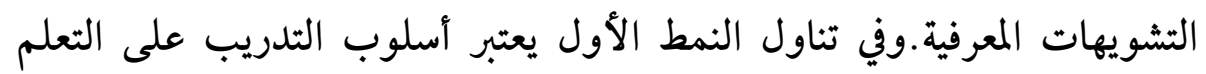

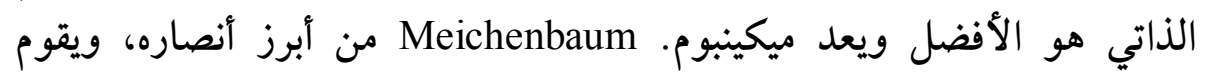
نموذجه على استدخال مجموعة من التعليمات الذاتية التي تحل محل محل الأفكار أنصاره

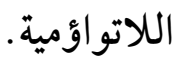

أما النموذج الثاني: والذي يهتم بمحتوى الأفكار والاعتقادات فيعمل

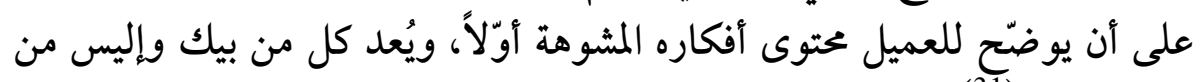
أبرز أنصاره (31).

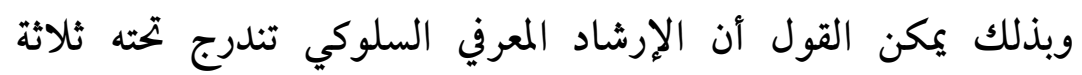

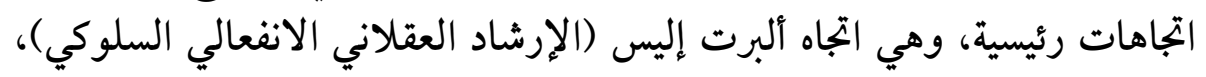

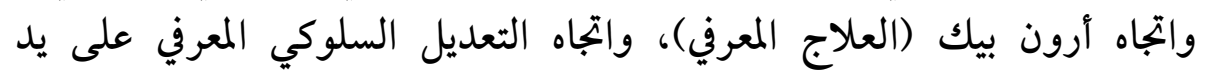

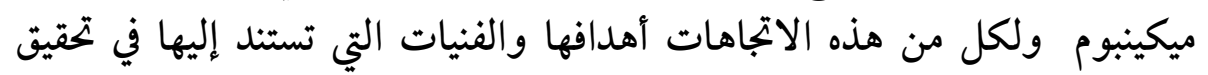

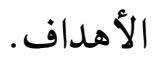




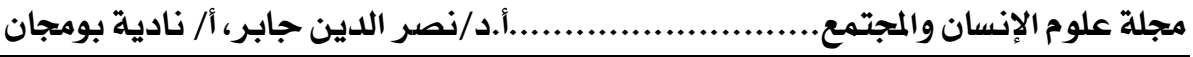

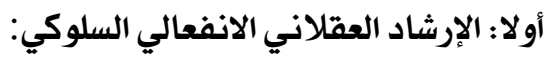

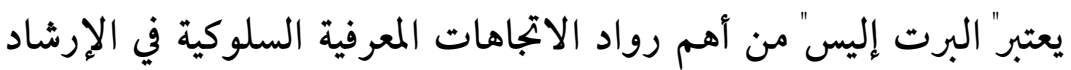
والعلاج النفسي، ولقد اقترن اسمه بالإرشاد العقلاني الانفعالي السلوكي.

وفي هذا يشير إليس إلى انه بدأ اتجاهه الإرشادي تحت تسمية الإرشاد

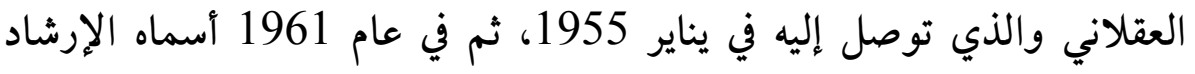

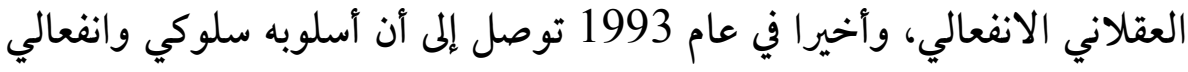
بنفس القدر كما هو معرفي فقام بتغيره إلى الإرشاد العقلاني الانفعالي السلوكي.

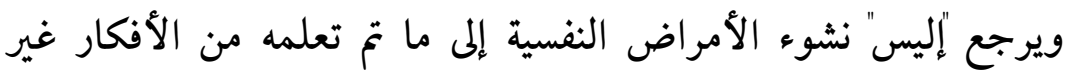
العقلانية من الناس المهمين خلال فترة الطفولة (بفعل التنشئة الاجتماعية)

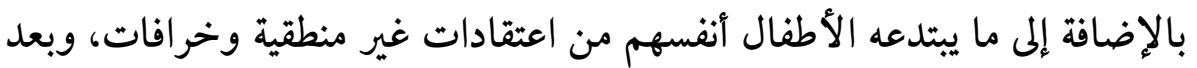

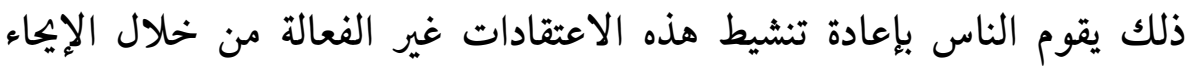

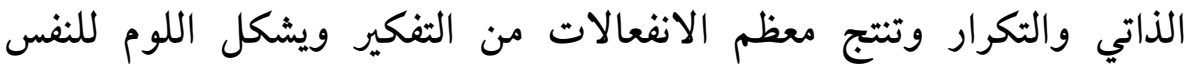
وللآخرين حجر الأساس في معظم الاضطرابات الانفعالية.

ولذلك فإن الاضطرابات الانفعالية تنتج عن أنماط التفكير الخاطئة وغير

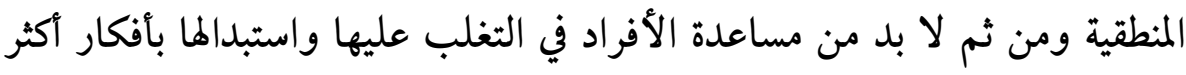

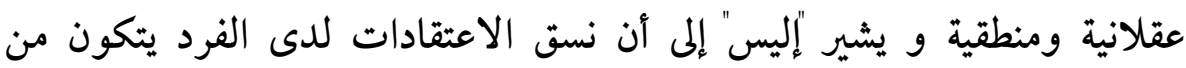

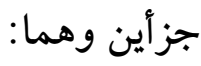

الأفكار اللاعقلانية، وتعتبر هي المسؤولة عن إحداث الاضطرابات

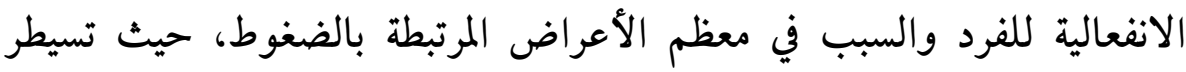

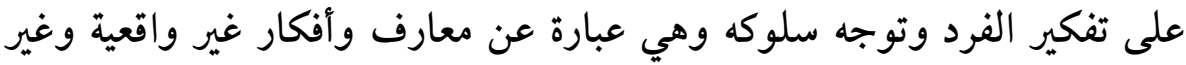

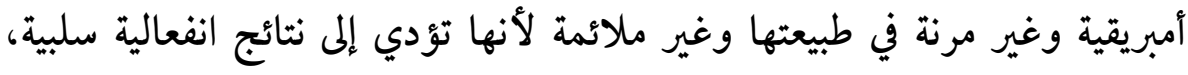

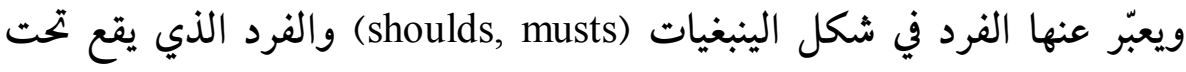

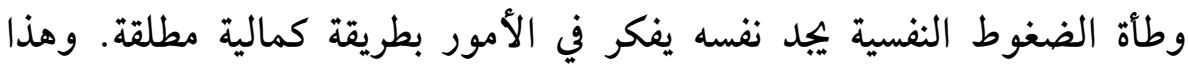




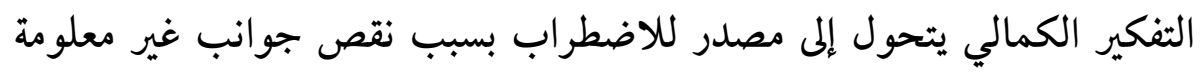

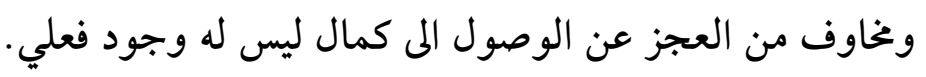

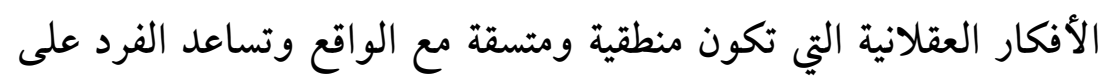

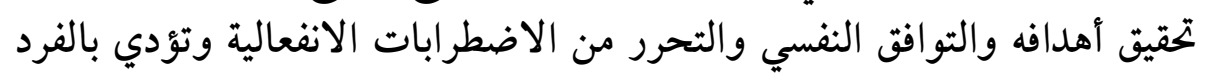

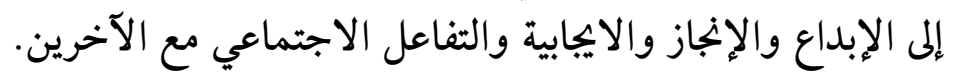

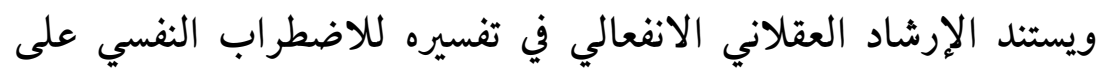

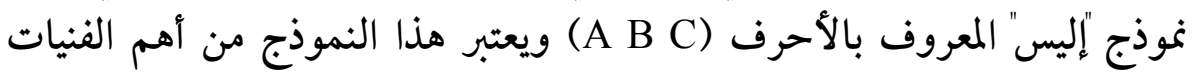
التي تستخدم في عملية الإرشاد العقلاني السلوكي.

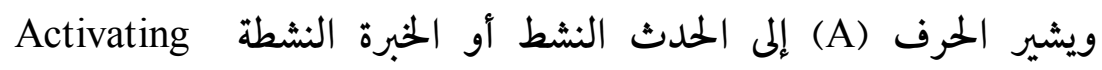

Experience.

ويشير الحرف (B) إلى نسق (نظام) المعتقدات (Belief system) لدى الفرد

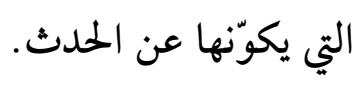

الحرف (C) فهو يشير إلى التيجة الانفعالية والسلوكية (Consequences)

$$
\text { التي تنجم عن اعتقادات الفرد. }
$$

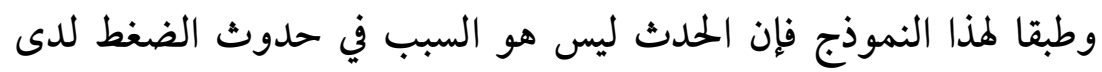

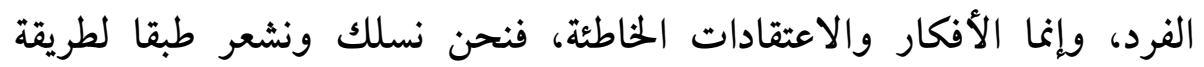
تفكيرنا.

وتقوم فنية (A B C) على إقناع الفرد بأن النتائج الانفعالية غير المرغوبة الماتية

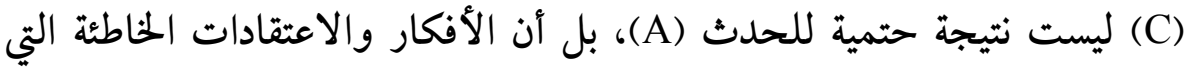

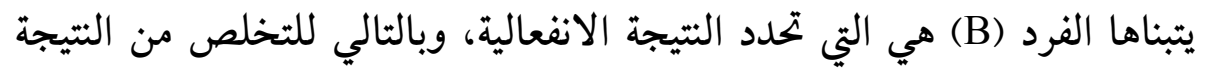

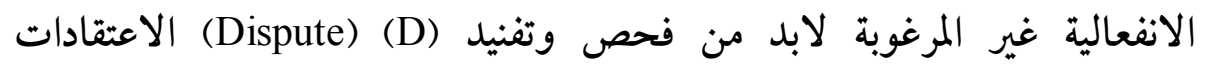

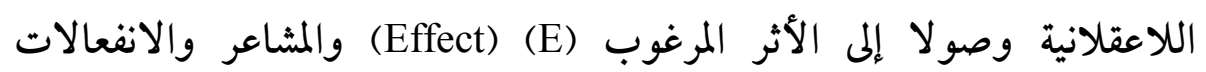
الايجابية ولقد أورد" إليس "(12) فكرة غير عقلانية (في المجتمع الأمريكي) هي (E) والماعر والانعات 


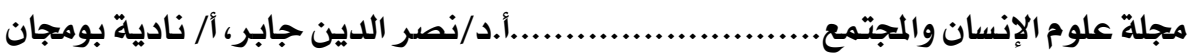

المسؤولة عن الاضطرابات الانفعالية (العصابية) يقابلها بجموعة الأفكار العقلانية

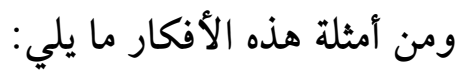

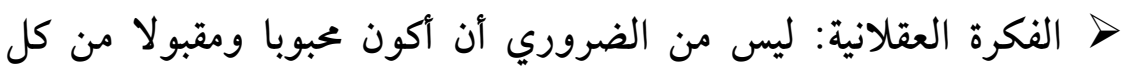

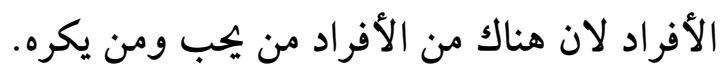

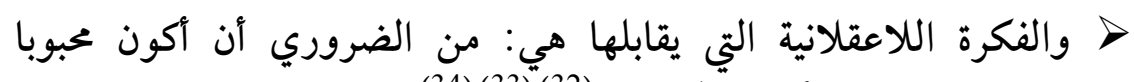

$$
\text { ومقبو لا من كل الأفراد الآخرين (32)"(33) (34). }
$$

ويستخدم الإرشاد العقلاني في عملية دحض الأفكار اللاعقلانية

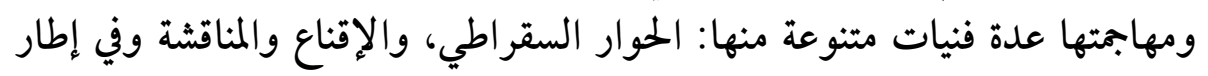

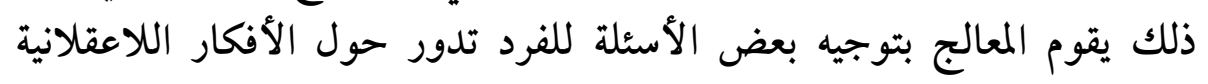

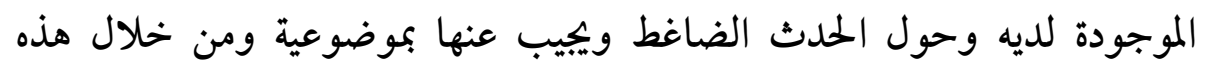

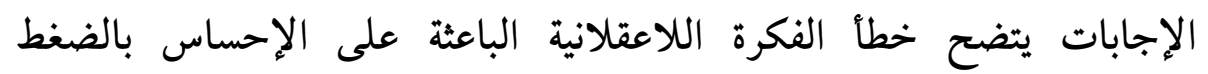

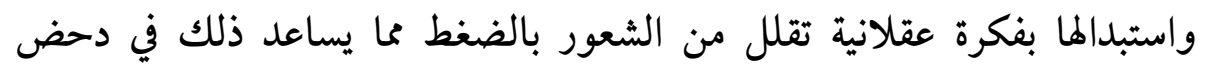

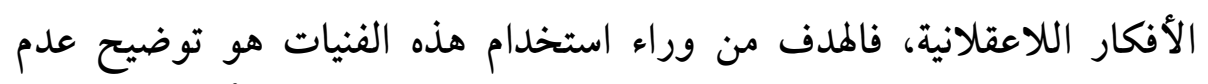
صحة الاعتقادات اللاعقلانية لدى الفرد منا يؤدي به في نهاية الأمر إلى التخلي عنها. ويكن استخدام فنيات أخرى نذكر منها مايلي:

• لعب الدور، ولعب الدور العكس (العكوس). النمذجة وأسلوب الفكاهة والمرح.

مهاجمة الشعور بالخجل والدونية، ومهاجمة المشاعر السلبية بشكل عام.

$$
\text { الواجبات المنزلية. }
$$

• أساليب الاشتراط الإجرائي مثل التعزيز والعقاب والتشكيل. أسلوب الثدريب على الاسترخاء. 
(35)

أسلوب التعريض، وقد يكون تخيليا أو تعريض واقعي.

أما خطوات الإرشاد العقلاني الانفعالي: فيؤكد "دريدان ودييوسيب" انه على الرغم من أن نموذح إليس (A B C D E) يعد هو جوهر أسلوب الإرشادي فئوكاد العقلاني الانفعالي السلوكي وتطبيقاته، فإن الخطوات المتنتابعة المتضمنة في تطبيق

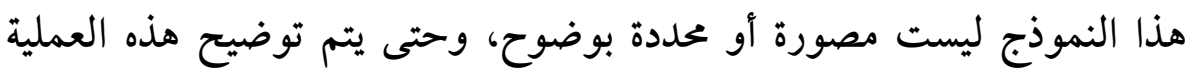

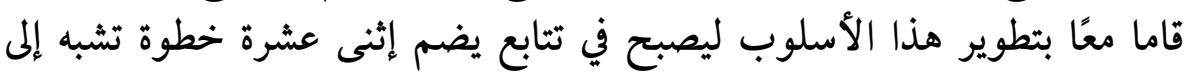
حد كبير تلك التي يتم استخدامها في الإرشاد وتشمل : 1. البحث عن المشكلة.

2. ت تحديد المشكلة المستهدفة.

3.

4. تقييم الأحداث النشطة (A)

5. تحديد وتقييم المشكلات الانفعالية الثانوية

6. التدريب على تحديد العلاقة بين الاعتقادات والنتائج (B - C) وتقييمها

7. تقييم الأفكار اللاعقلانية (B)

8. ربط الأفكار اللاعقلانية (B) بالنتائج (C) (الاضطراب الانفعالي) 9.9

10. إعداد العميل لتعميق اعتقاده في أفكاره العقلانية من خلال المناقشة. 11. إعطاء العميل واجبات منزلية حتى يتسنى له الممارسة.

$$
\text { 12. مراجعة الواجبات المنزلية (36). }
$$

ولقد أوضحت العديد من الدراسات فاعلية الإرشاد العقلاني الانفعالي

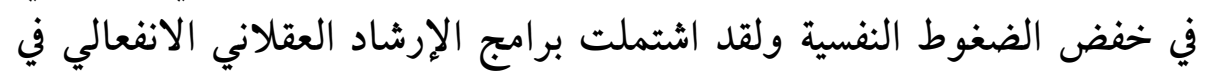




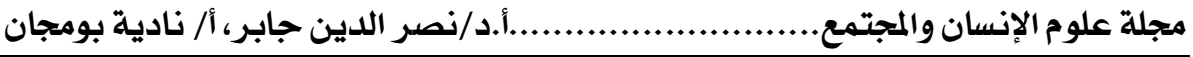

خفض الضغوط على عدة خطوات وهي: تعريف المشاركين في البرنامج بمفهوم

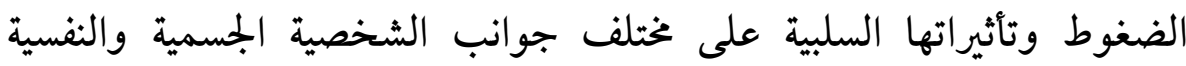

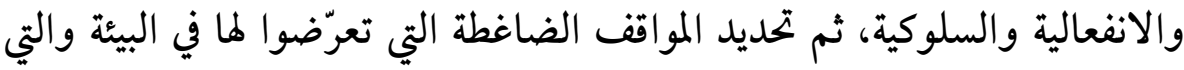

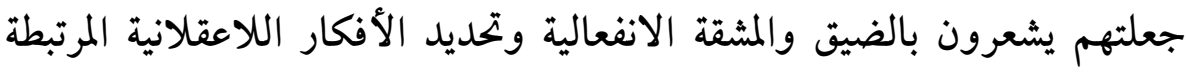

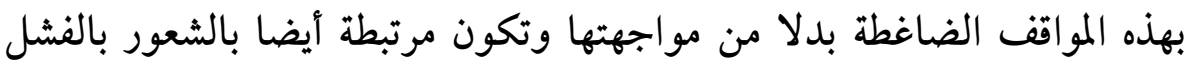

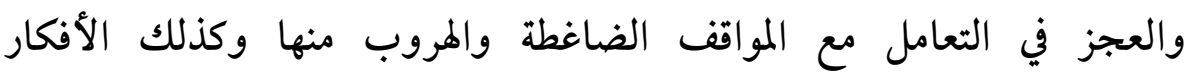

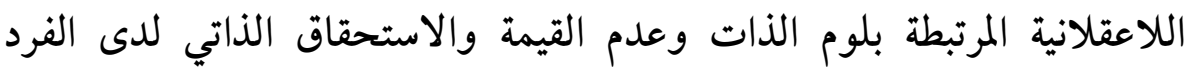
نتيجة الفشل في مواجهة المواقف الضاغطة (37).

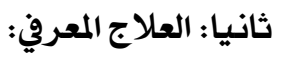

يُعد النموذج الذي قدمه "بيك" من ابرز النماذج العلاجية في هذا الاتجاه

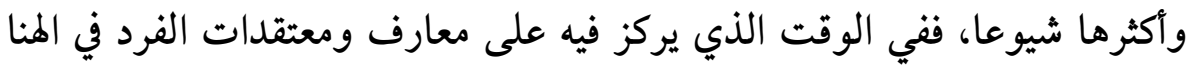

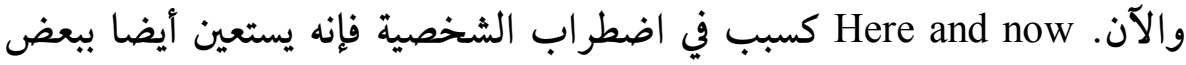

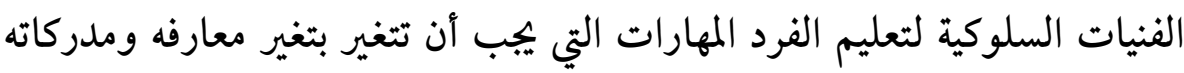

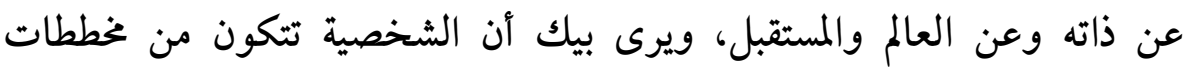

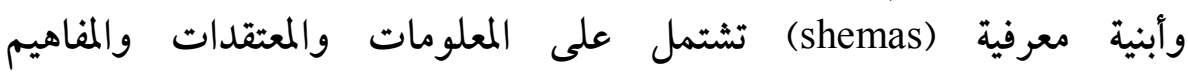

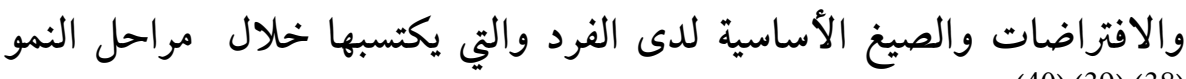

ويشير بيك إلى أن الاضطرابات النفسية لدى الأفراد لا تنشأ من الأحداث

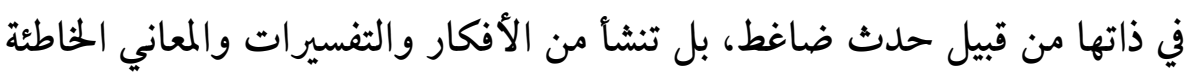

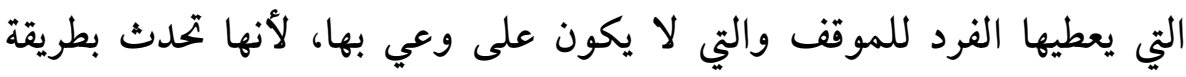

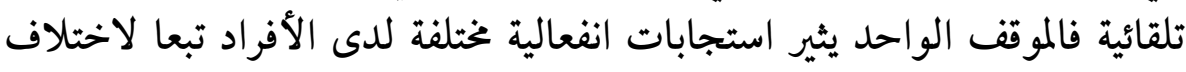

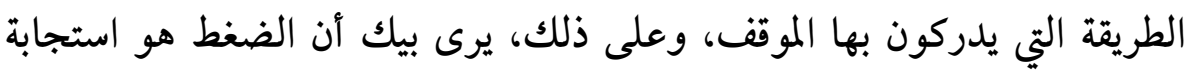

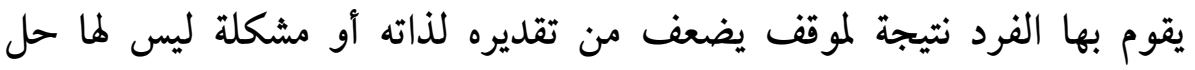


تسبب له إحباطا وتعوق اتزانه أو موقف يثير لديه أفكار عن الشعور بالعجز واليأس (41).

وذهب بيك إلى أن الأفكار التلقائية السلبية تؤدي إلى التشويه المعرفي وان

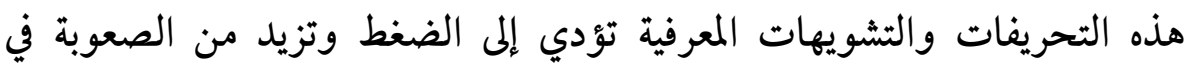
مواجهة المواقف الضاغطة وبعبارة واضحة يمكن القول أن الأفكار التلقائية السلبية التئية

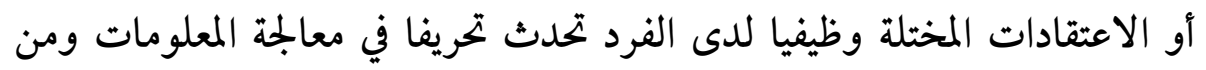

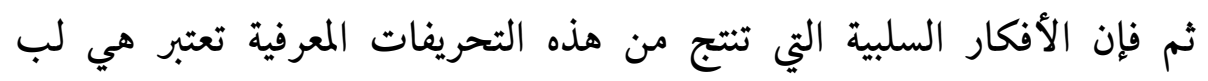
وصميم الاضطرابات النفسية لدى الفرد.

وتتحدد التحريفات المعرفية التي من شانها أن تؤدي إلى الفشل في مواجهة المواقف الضاغطة والتوافق معها في عدة أنواع كما يلي: التفكير بطريقة الكل أو الاشيء، أي التفكير في الحصول على كل شيء أو لا شيء. - ألفكير بطريقة

التهويل والتضخيم ويعني تحميل الأمور أكثر ما تستحق. القفز إلى الاستنتاجات ويعني التوصل إلى استنتاجات خاطئة دون وجود

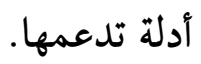
• التعميم الزائد ويعني تفسير جميع الأحداث في ضوء قاعدة واحدة. • التفكير الثنائي ويعني التفكير بشكل بعيد عن الوسطية (أبيض، أسود).

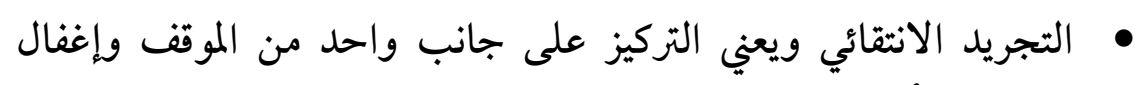

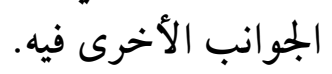

فهذه التحريفات المعرفية تتوسط العلاقة بين الأحداث والشعور بالضغط

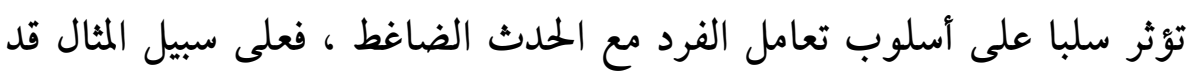

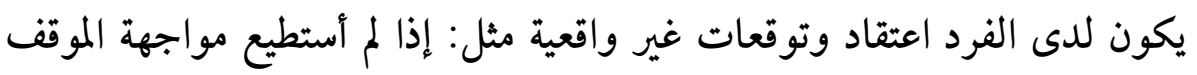




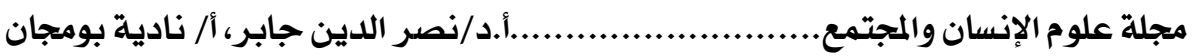

الضاغط فهذا يمثل بالنسبة لي كارثة وأنني فاشل. وبالتالي يقلل الفرد من شأن

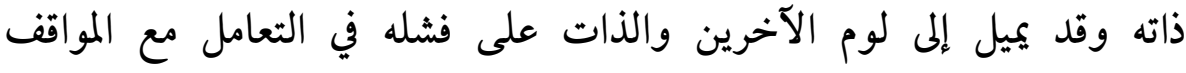

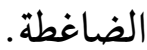

وهنا ينبغي التاكيد على الحذر من الوقوع في التهويل والتضخيم وغيرها

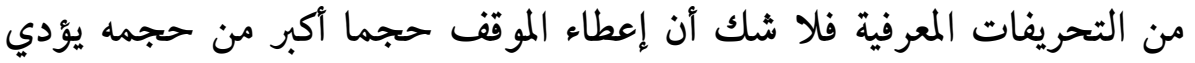

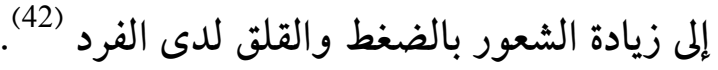

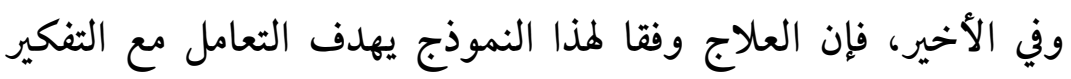

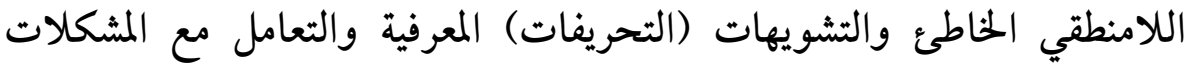

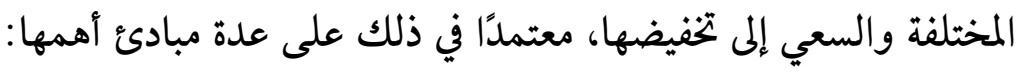

المشاركة العلاجية وتوطيد المصداقية مع المريض، وتقليل أو اختزال

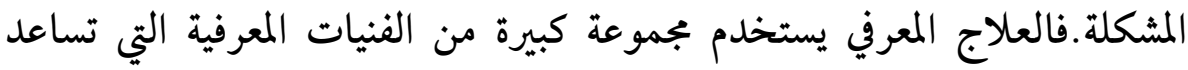

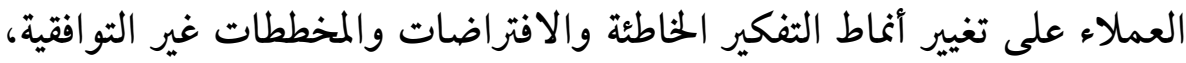

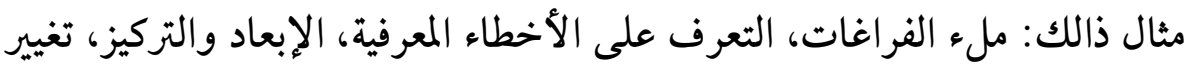
القواعد (مقاومة الينغيات)......

وإلى جانب هذا، يستخدم العلاج المعرفي الفنيات السلوكية التي تساعد في

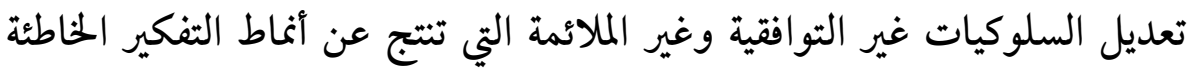

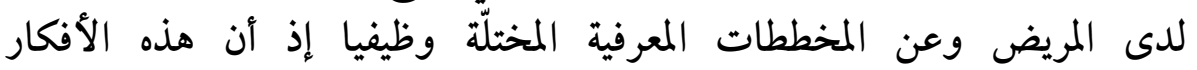

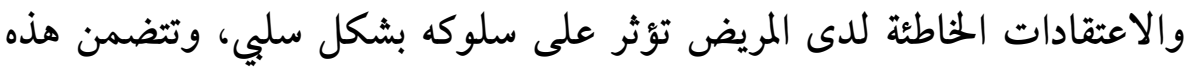

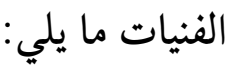

جداول الأنشطة، المهام المتدرّجة، الوجبات المنزلية، لعب الدور، التدريب

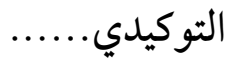

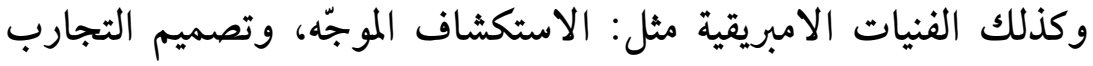

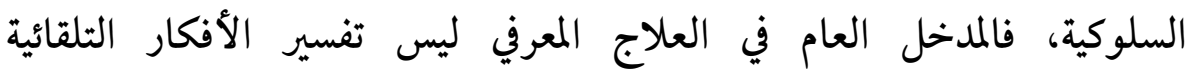


والاعتقادات غير التوافقية فقط، بل أيضا فحصها من خلال التجريب والتحليل المنطقي لما.

وبجمل القول انه على الرغم من أن جميع العلاجات المعرفية تعترف بدور

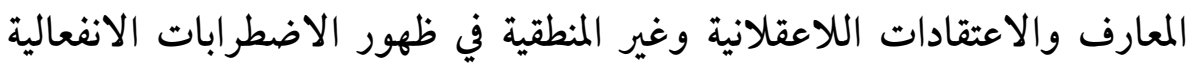

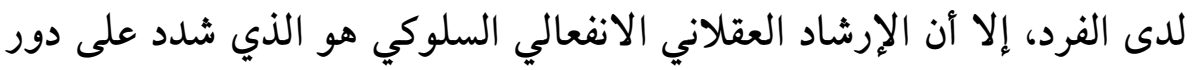

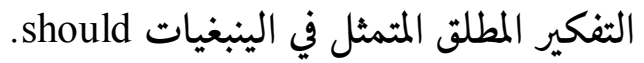

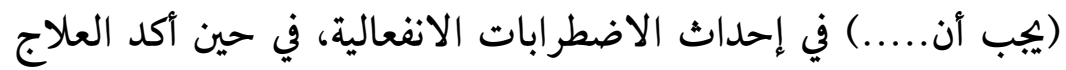

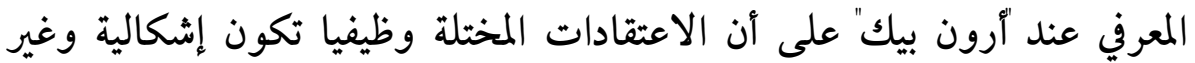

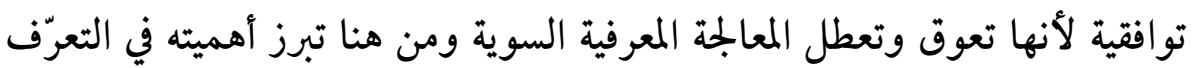

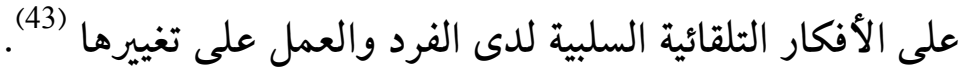

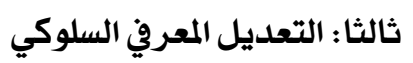

وفي إطار الثدخلات المعرفية السلوكية ظهر اتجاه علاجي معرفي آخر المري

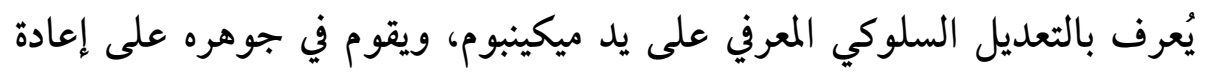

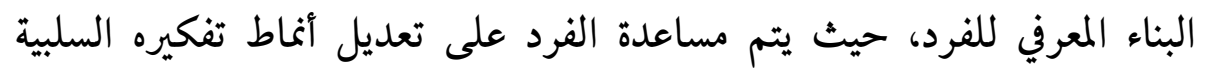

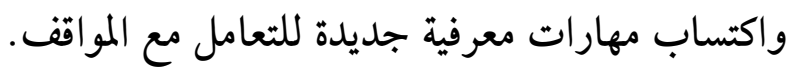

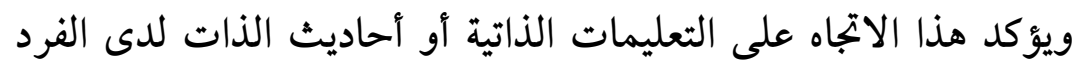

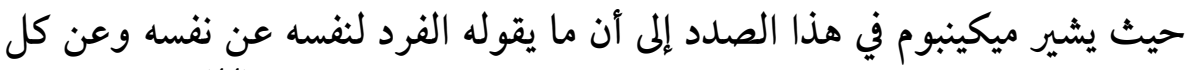

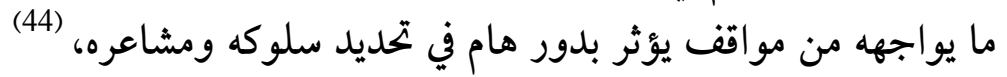
فالحديث الذاتي المرتبط بموقف الضغط النفسي والقدرة على المواجهة له بله

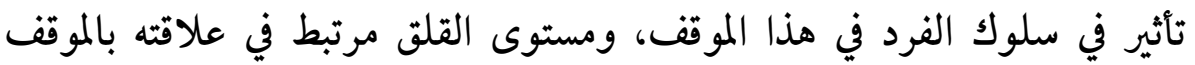

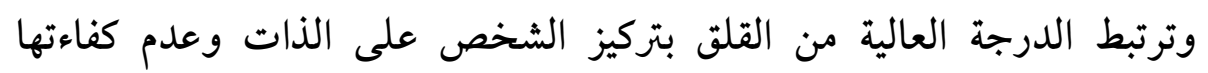

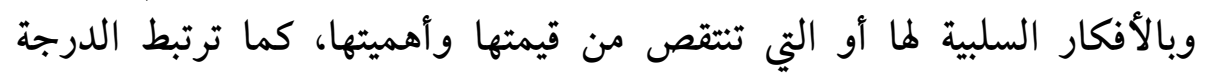

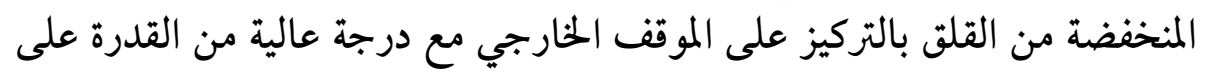




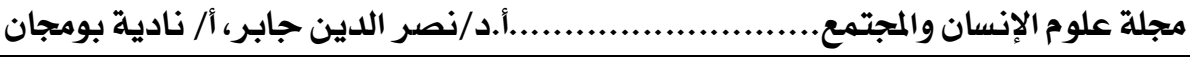

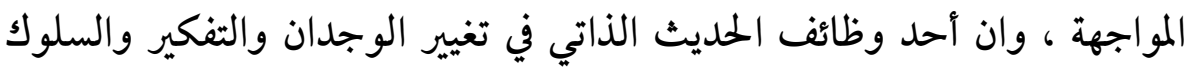

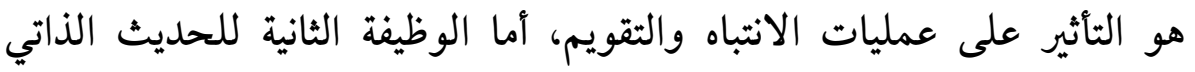

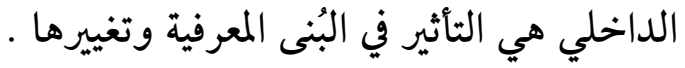

إن مكونا مثل البنية المعرفية يعتبر ضروريا بالنسبة لطبيعة التعليمات

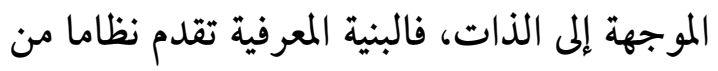

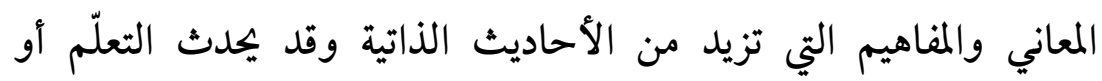

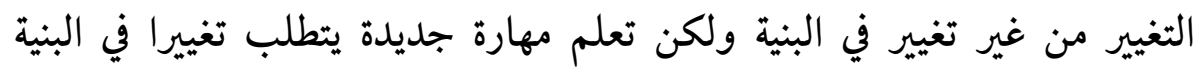

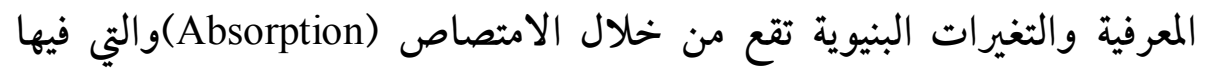

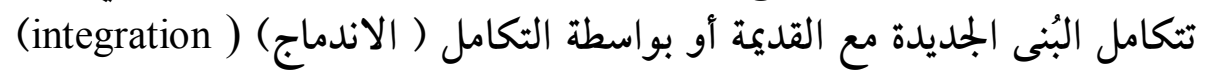

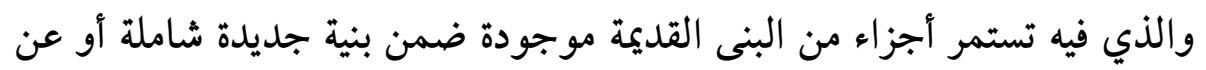

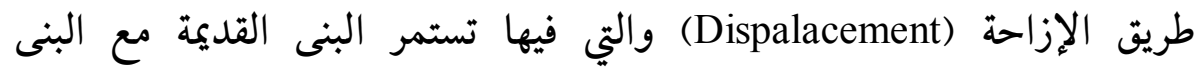

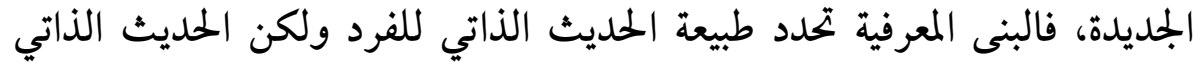
يغير البنى المعرفية حيث يسميه ميكينبوم الدورة الفعالة الدائرة الخيرة(Cycle

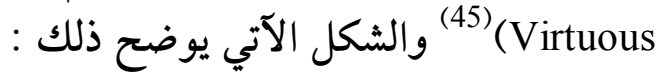

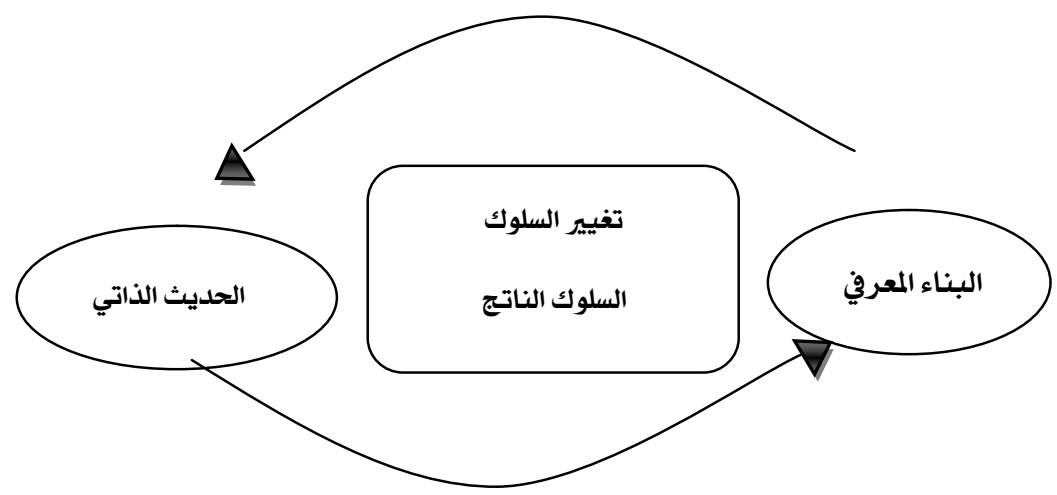

افتراض ميكينبوم بين البناء المعرفي والحديث الذاتي 
وقد صاغ ميكينبوم Meichenhaum طريقتين حظيت في العلاج الاستعرافي

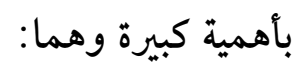
التدريب على التعليم الذاتي (Self- Instruction training).

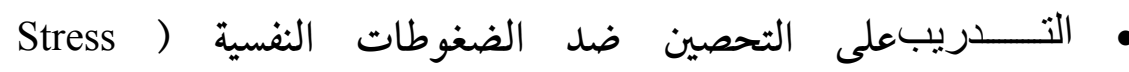
.46) (Inoculation Training 1/ التدريب على التعليم الذاتي ( التدريب على التوجيهات الذاتية): ويتضمن هذا الأسلوب التعرّف على الأفكار والتعبيرات الذاتية السلبية

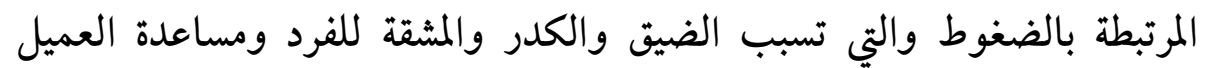

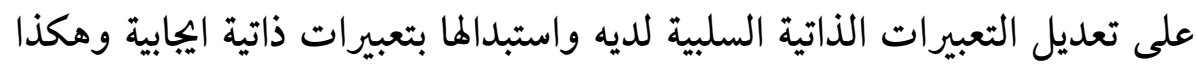

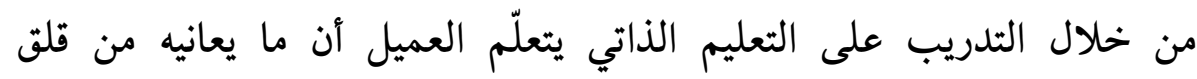

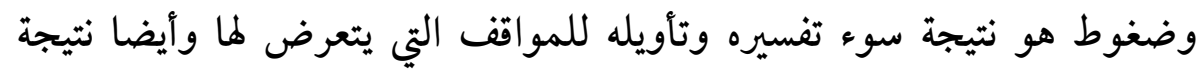

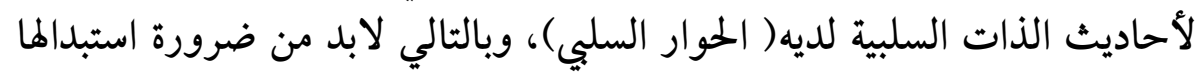

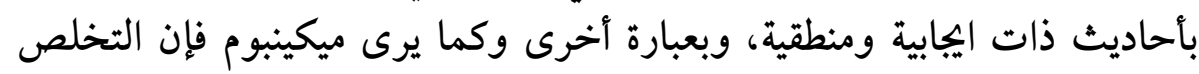

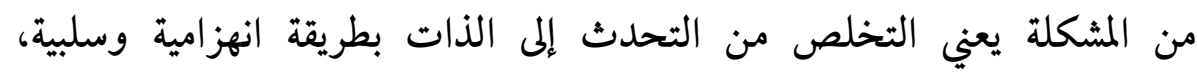

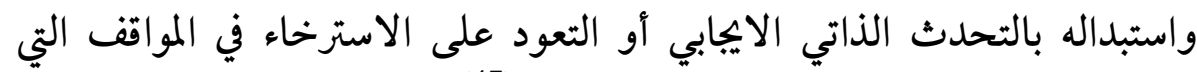
تبعث على القلق وعدم الراحة في نفس الإنسان (47).

2. التدريب على مقاومة القلق والتوتر أو التدريب على التحصين ضد الضغوط التس تشبه هذه الطريقة عملية التحصين البيولوجي ضد الأمراض العامة، وهي

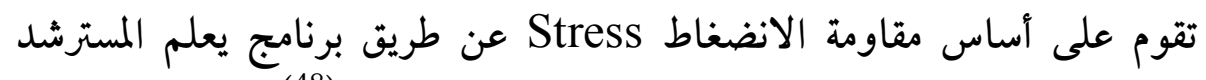

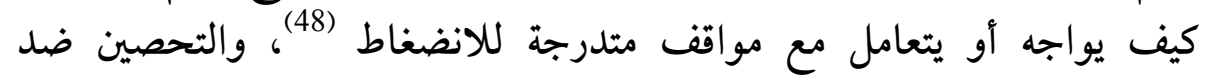

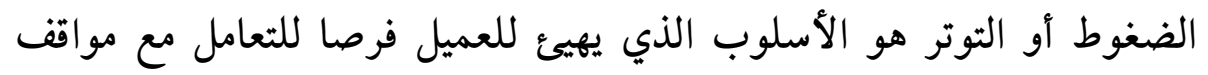

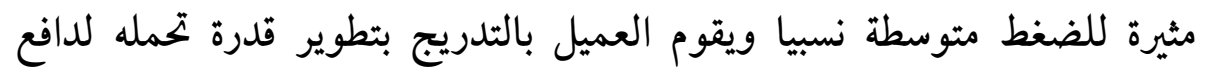

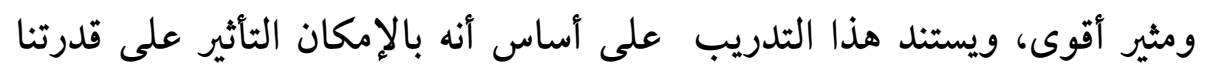




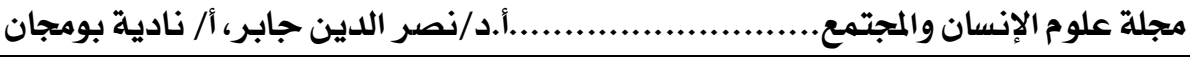

الاحتمالية للتعامل مع الضغوط من خلال تعديل معتقداتنا وعباراتنا الذاتية في

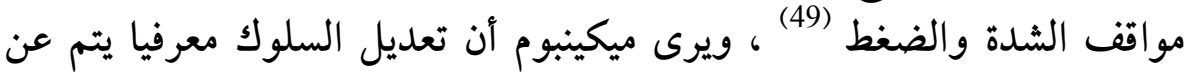

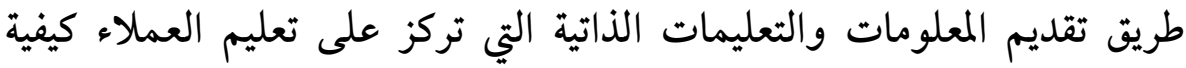

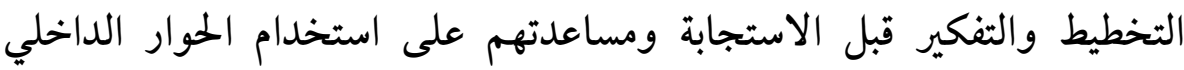

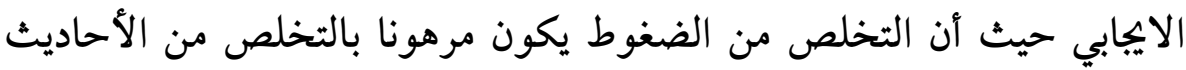

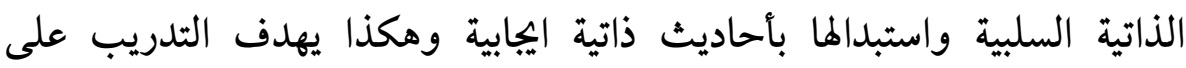
التحصين ضد الضغوط إلى تدريب الفرد على أحاديث الذات الاييجابية (50)

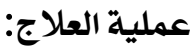

$$
\text { تتألف عملية العلاج عند ميكينبوم من ثلاث مراحل: }
$$

المرحلة الأولى: مراقبة الذات Self Observation : وفيها يعرف المسترشد كيف

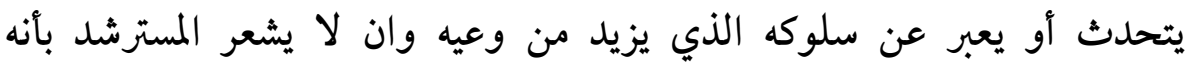

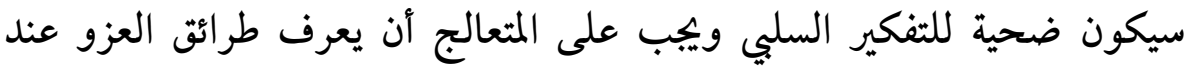

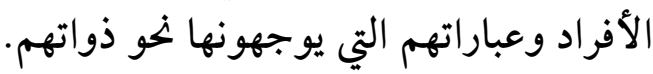

thoughts Incompatible - المرحلة الثانية: السلوكيات والأفكار غير المتكافئة and behaviors

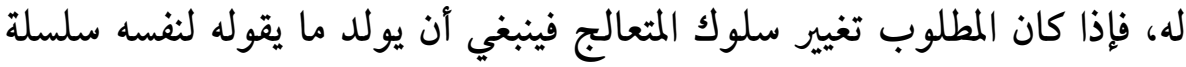

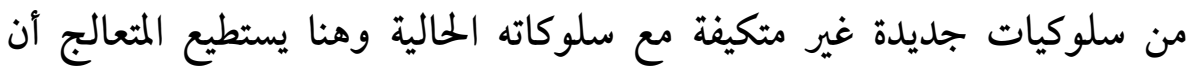
يتجنب السلوكيات غير المناسبة ويختار السلوكيات المناسبة وفقا للأفكار الجديدة.

المرحلة الثالثة: المعرفة المرتبطة بالتغيير: Cognition concerningchange:وفيها

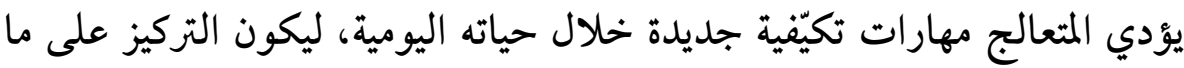

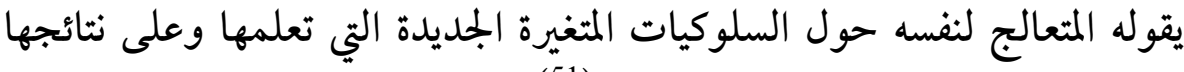

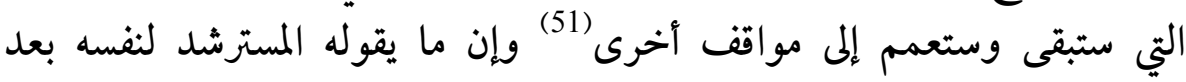

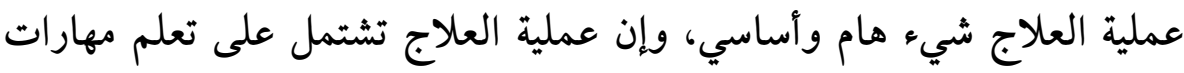
سلوكية جديدة ، وحوارات داخلية جديدة وأبنية معرفية جديدة. 
إن على المرشد أن يهتم بالعمليات الأساسية الثلاث هي : (أ) البناءات المعرفية.

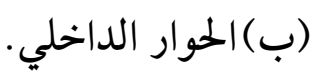
(ج) السلوكيات الناتجة عن ذلك. وعليه فان عملية العلاج تبدأ بتحديد السلوك القديم المراد تغييره،

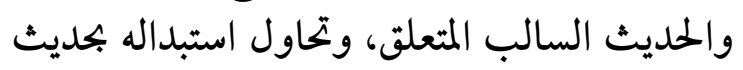

داخلي جديد متكيف ينتج سلوكا متكيفا يؤثر في تكوين بناءات معرفية إنداث

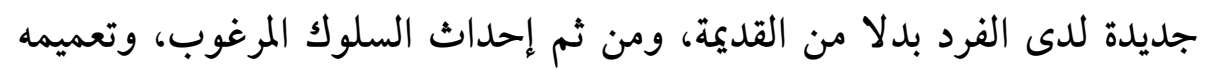
ومحاولة تثبيته (52).

الفنيات العلاجية :

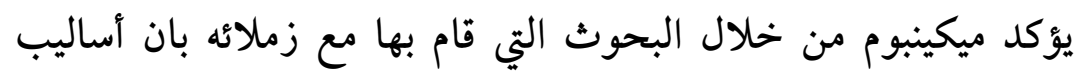

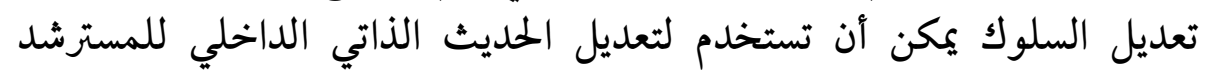

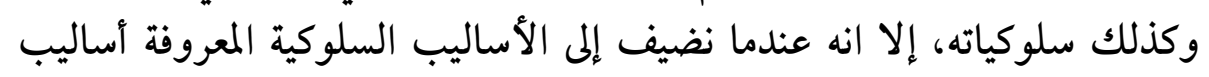

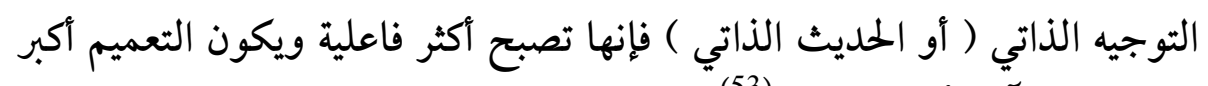

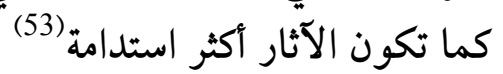

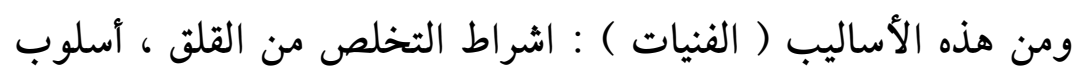

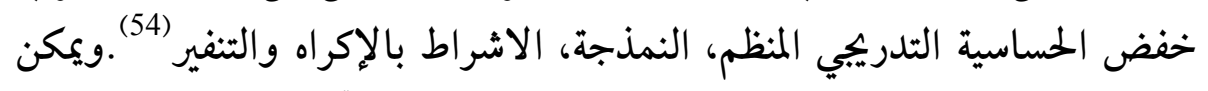

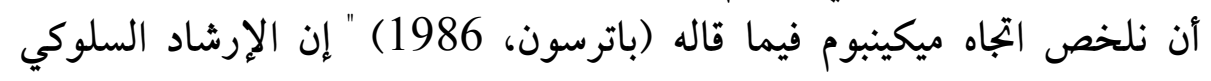

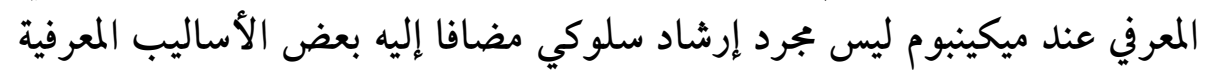

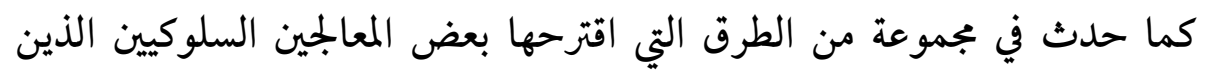

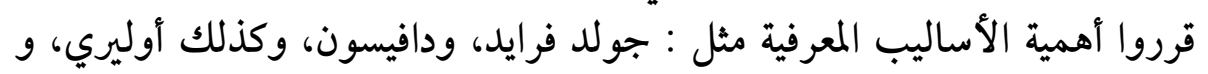

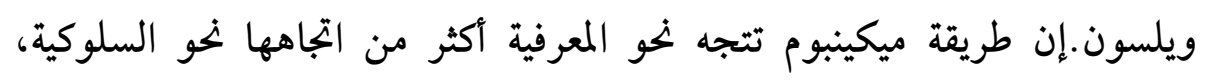




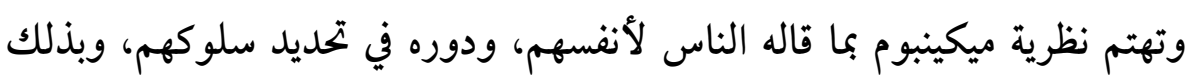

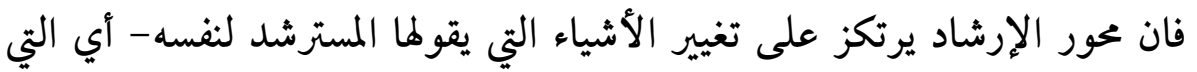

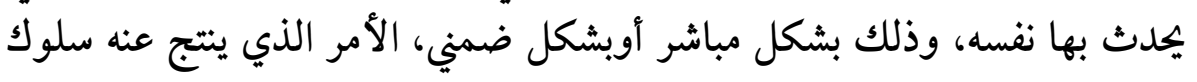

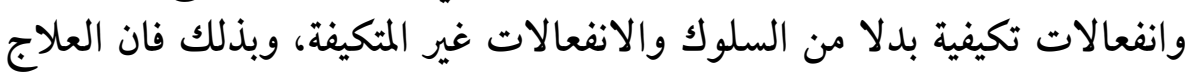

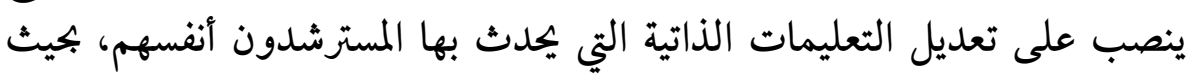

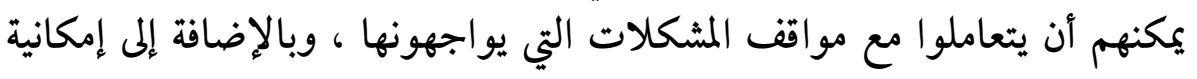

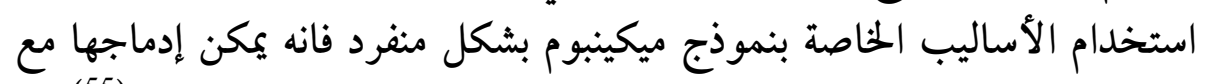

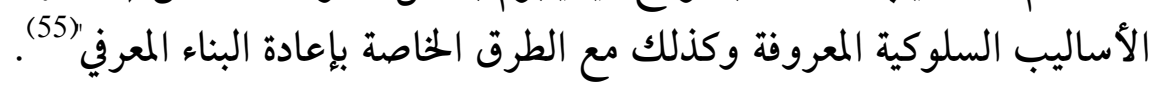




\section{الخاتمة}

تناولنا في هذا المقال ،التعريف بالإرشاد المعرفي السلوكي وتطوره، كما تم التحات

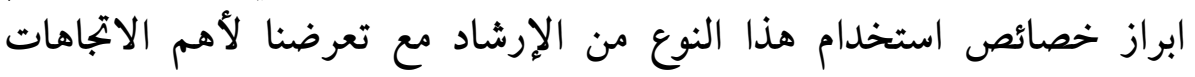

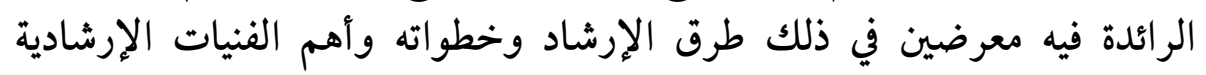
المستخدمة.

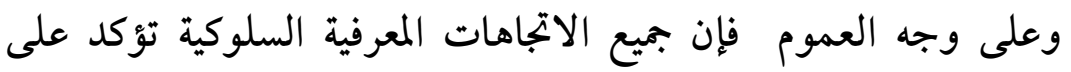

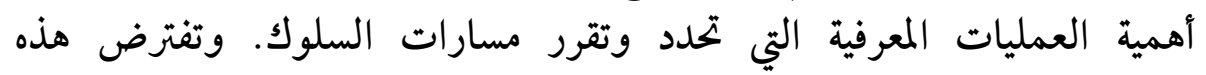

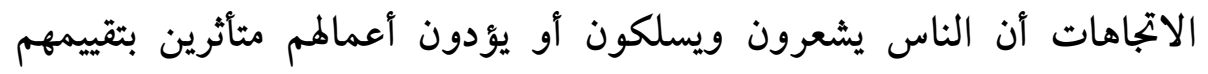

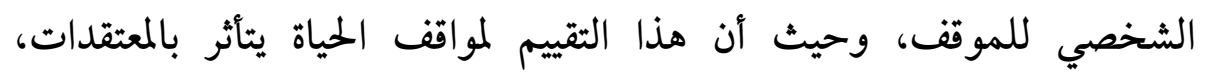

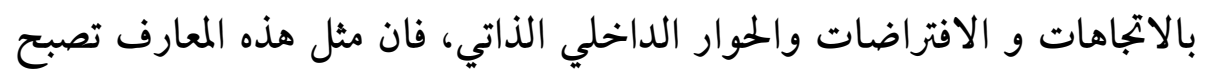
المركز الرئيسي للإرشاد. 


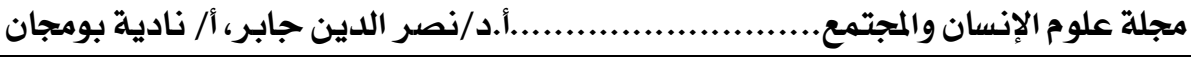

\section{هوامش البحث:}

وصل الله السواط: فاعلية برنامج إرشادي معرفي سلوكي في تحسين مستوى النضج المهني

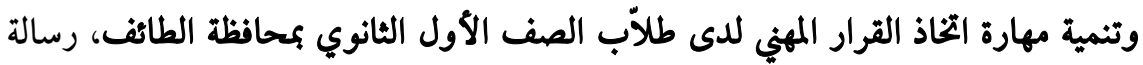

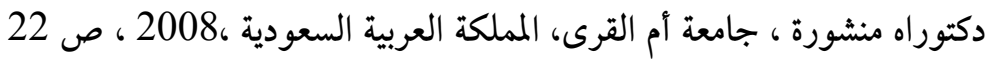
(2) عادل عبد الله محمد: العلاج المعرفي السلوكي اسس وتطبيقات، دار الرشاد، مصر، 2000، ص 24.

(3) بطرس حافظ بطرس: المثكلات النفسية وعلاجها، دار المسيرة، عمان، 2008، ص 156. (4) محمد قاسم عبد الله : نظريات الإرشاد والعلاج النفسي، دار الفكر، عمان، 2012، ص1. (5) حامد زهران: التوجيه والإرثاد النفسي، عالم الكتب، القاهرة، 1998، ط3، ص 363. سهام أبو عيطة: مبادى الإرشاد النفسي، دار الفكر، عمان، 2002، ط2 ، ص147. (7) طه عبد العظيم حسين : الإرشاد النفسي، دار الفكر، عمان، 2004، ص74. (8) طه عبد العظيم حسين : العلاج النفسي المعرفي مفاميم وتطبيقات، 2007، دار الوفاء،

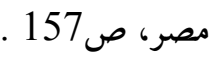
روبرت ليهي: العلاج النفسي المعرفي في الإضطرابات النفسية، ترجمة: جمعة سيد يوسف

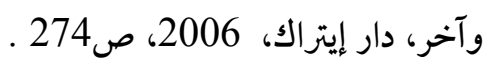

(10) زيزي السيد إبراهيم: العلاج المعرفي للإكتئاب، دار غريب، القاهرة، 2006، ص207 (11) طه عبد العظيم حسين (2007)، مرجع سبق ذكره ،ص ص ص 157 ، 158، 159 (12) ناصر المحارب: المرشد في العلاج الإستعرافي السلوكي، دار الزهراء، الرياض، 2000، ص 01. (13) تيسير إلياس شواش: دليل الأخصائين والمرثدين النفسيين في التعامل مع النساء ضحايا

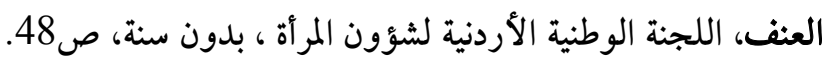


http://www.women.jo/admin/document/dalel.pdf.

(14) محمد محمود، علي أحمد : العلاج النفسي السلوكي المعرفي الحديث، دارالزهراء، الرياض، 2011، طم ط 191

$$
\text { (15) زيزي السيد إبراهيم، مرجع سبق ذكره، ص ص 222، } 121 .
$$

(16) لويس مليكة: العلاج السلوكي وتعديل السلوك ، دار القلم، الكويت، 1990، ص244. (17) علاء الدين بدوي فرغلي: مهارات العلاج المعرفي السلوكي، مكتبة النهضة المصرية،2008،

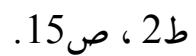

$$
\begin{aligned}
& \text { (18) لويس مليكة ، مرجع سبق ذكره ،ص119. } \\
& \text { (19) ناصر المحارب، مرجع سبق ذكره، ص1. }
\end{aligned}
$$

(20) ابتسام عبدالله الزغي: العلاج المعرفي السلوكي، تعريفه، أمدافه، قواعدهكلية التربية-قسم

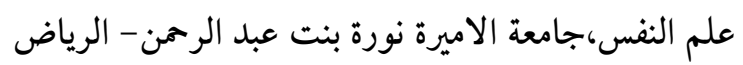

http://www.eawraq.com/news.php?action=view\&id=285.

(21) عفاف وعبد الله: مدى ممارسة المرشد النفسي لفنيات المقابلة الإرشادية من وجهة نظر

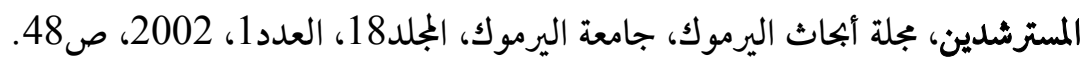

جمال الخطيب: تعديل السلوك الإنساني، مكتبة الفلاح، الأردن، 2007، ط2333، ص

(23) خالد عسل: العلاج المعرفي السلوكي للنمط السلوكي ( I )، دار الوفاء، مصر، 2008، ص 67 . n

جمال الخطيب، مرجع سبق ذكره ،ص 334

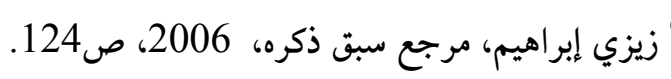

زيزي إبراهيم، المرجع السابق، ص ص 125 -126. 


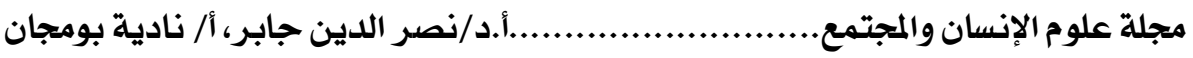

$$
\begin{aligned}
& \text { (27) جمال الخطيب، مرجع سبق ذكره، ص334 } \\
& \text { (28) علاء الدين بدوي فرغلي ، مرجع سبق ذكره، ص34. } \\
& \text { عادل عبد الله محمد: مرجع سبق ذكره، ص26. }
\end{aligned}
$$

(30) Revue de la Socité Algérienne de Psychiatrie: Thérapie cognitivocomportementale, Numéro Spéciale :N 10 Décembre 2010.

(31) طه عبد العظيم، سلامة عبد العظيم: استراتيجيات إدارة الضغوط التربوية والنفسية، دار

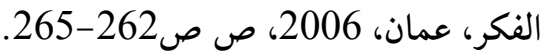

$$
\begin{aligned}
& \text { محمد محمود علي وآخر، مرجع سبق ذكره، ص177) } 177 . \\
& \text { محمد قاسم عبد الله، مرجع سبق ذكره، ص ص 167،168 }
\end{aligned}
$$$$
\text { حسني محمد عوض: امم النظريات الحديثة في الإرشاد وتطبيقاتها التربوية، } 2006 .
$$

http://www.stqou.com/vb/attachment.php?attachmentid=8620.

عبد اللطيف دبور، وعبد الحكيم الصافي: الإرشاد المدرسي بين النظرية والثطبي، دار

$$
\begin{aligned}
& \text { الفكر، 2007، ص130. } \\
& \text { (36) خالد محمد عسل، مرجع سبق ذكره، صل71. } \\
& \text { (37) طه عبد العظيم وآخر، (2006)، مرجع سبق ذكره ص ص 266-267. } \\
& \text { (38) طه عبد العظيم وآخر، المرجع السابق، ص267. } \\
& \text { خالد محمد عسل، مرجع سبق ذكره، ص72(39) } \\
& \text { (40) محمد محمود علي وآخر، مرجع سبق ذكره، ص ص 177-178. } \\
& \text { (41) طه عبد العظيم و آخر، مرجع سبق ذكره، ص } 268 . \\
& \text { (42) (المرجع السابق، ص } 269 .
\end{aligned}
$$




$$
\text { المرجع السابق، ص271) المرجع السابق، ص271. }
$$

(45) صالح مهدي وآخر : التحدث مع الذات ، دار صفاء، عمان ،2011، ص ص43-45 ميشال برودا: ممارسة العلاج النفسي، ترجمة: سامر رضوان ،دار الكتاب الجامعي، غزة -

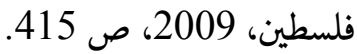
جمال الخطيب، مرجع سبق ذكره، ص 350 (47) (48) محمد الشناوي، نظريات الإرشاد والعلاج النفسي،دار غريب، القاهرة،1994 ص135. ${ }^{(49)}$ http://www.acofps.com/vb/archive/index.php/t-5245.html.

$$
\text { (50) طه عبد العظيم وآخر، مرجع سبق ذكره، ص } 272 .
$$

(51) صفاء ديوب : فاعلية برنامج علاجي معرفي - سلوكي في خفض اعراض الإحتراق جامعة دمشق، 2008 .

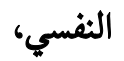

بطرس حافظ، مرجع سبق ذكره ،ص 183.

(53) الشناوي، مرجع سبق ذكره، ص 133

(54) محمد قاسم عبد الله، مرجع سبق ذكره، ص 124. بطرس حافظ، مرجع سبق ذكره، ص185(.5 